\title{
A comprehensive systematic review of CSF proteins and peptides that define Alzheimer's disease
}

\author{
Cristina M. Pedrero-Prieto', Sonia García-Carpintero', Javier Frontiñán-Rubio', Emilio Llanos-González ,

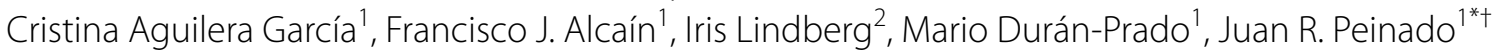 \\ and Yoana Rabanal-Ruiz ${ }^{1 *+}$
}

\begin{abstract}
Background: During the last two decades, over 100 proteomics studies have identified a variety of potential biomarkers in CSF of Alzheimer's (AD) patients. Although several reviews have proposed specific biomarkers, to date, the statistical relevance of these proteins has not been investigated and no peptidomic analyses have been generated on the basis of specific up- or down- regulation. Herein, we perform an analysis of all unbiased explorative proteomics studies of CSF biomarkers in AD to critically evaluate whether proteins and peptides identified in each study are consistent in distribution; direction change; and significance, which would strengthen their potential use in studies of AD pathology and progression.
\end{abstract}

Methods: We generated a database containing all CSF proteins whose levels are known to be significantly altered in human AD from 47 independent, validated, proteomics studies. Using this database, which contains 2022 AD and 2562 control human samples, we examined whether each protein is consistently present on the basis of reliable statistical studies; and if so, whether it is over- or under-represented in AD. Additionally, we performed a direct analysis of available mass spectrometric data of these proteins to generate an AD CSF peptide database with 3221 peptides for further analysis.

Results: Of the 162 proteins that were identified in 2 or more studies, we investigated their enrichment or depletion in AD CSF. This allowed us to identify 23 proteins which were increased and 50 proteins which were decreased in AD, some of which have never been revealed as consistent AD biomarkers (i.e. SPRC or MUC18). Regarding the analysis of the tryptic peptide database, we identified 87 peptides corresponding to 13 proteins as the most highly consistently altered peptides in AD. Analysis of tryptic peptide fingerprinting revealed specific peptides encoded by CH3L1, VGF, SCG2, PCSK1N, FBLN3 and APOC2 with the highest probability of detection in AD.

Conclusions: Our study reveals a panel of 27 proteins and 21 peptides highly altered in AD with consistent statistical significance; this panel constitutes a potent tool for the classification and diagnosis of AD.

Keywords: Alzheimer's Disease, Biomarkers, Proteomic, Peptidomics

\footnotetext{
*Correspondence: JuanRamon.Peinado@uclm.es; Yoana.Rabanal@uclm.es †Juan R. Peinado and Yoana Rabanal-Ruiz shared senior authorship ${ }^{1}$ Department of Medical Sciences, Ciudad Real Medical School, Oxidative Stress and Neurodegeneration Group, Regional Center for Biomedical Research, University of Castilla-La Mancha, Ciudad Real, Spain Full list of author information is available at the end of the article
}

\section{Background}

Due to its high prevalence within the world population, Alzheimer's disease (AD) is likely the most studied neurodegenerative disease [1]. A variety of studies have characterized $\mathrm{AD}$ pathology from a cognitive point of view [2] and/or using neuroimaging approaches [3]. While these approaches are necessary in order to distinguish the

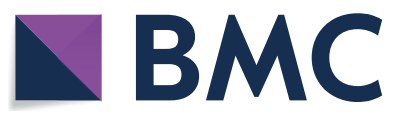

(c) The Author(s) 2020. This article is licensed under a Creative Commons Attribution 4.0 International License, which permits use, sharing, adaptation, distribution and reproduction in any medium or format, as long as you give appropriate credit to the original author(s) and the source, provide a link to the Creative Commons licence, and indicate if changes were made. The images or other third party material in this article are included in the article's Creative Commons licence, unless indicated otherwise in a credit line to the material. If material is not included in the article's Creative Commons licence and your intended use is not permitted by statutory regulation or exceeds the permitted use, you will need to obtain permission directly from the copyright holder. To view a copy of this licence, visit http://creativeco mmons.org/licenses/by/4.0/. The Creative Commons Public Domain Dedication waiver (http://creativecommons.org/publicdomain/ zero/1.0/) applies to the data made available in this article, unless otherwise stated in a credit line to the data. 
various hallmarks of $\mathrm{AD}$ progression, there is still a need to identify reliable biomarkers for the effective diagnosis and prognosis of $\mathrm{AD}$.

Most studies aimed at the detection of AD biomarkers have been carried out on biological fluids such as blood or cerebrospinal fluid (CSF) (reviewed in [4-6]). The use of CSF represents the best approach to identify AD biomarkers (reviewed in [6]) since this fluid contacts the brain interstitial fluid directly and thus more accurately reflects biochemical changes related to central nervous system (CNS) processes. Indeed, studies of AD CSF have consistently demonstrated that amyloid- $\beta$ (A $\beta 42)$, total tau (T-tau), and phosphorylated tau (P-tau) constitute CSF biomarkers relevant to AD diagnosis [6-8]. However, the heterogeneity of $\mathrm{AD}$ pathology calls for a deeper review of potential AD CSF biomarkers. Biomarker use may eventually help to predict disease progression, from asymptomatic stages to full-blown AD. Accordingly, over 100 different proteomic studies of potential CSF biomarkers in $\mathrm{AD}$ have been conducted during the past 15 years.

A number of reviews have been recently published which have examined these past studies and have proposed specific biomarkers for AD in CSF $[9,10]$. However, only 3 proteomic reviews with controlled analyses directly comparing biomarkers in $\mathrm{AD}$ and control CSF have been conducted thus far. In 2016, Olsson et al. described which of the common biomarkers in both CSF and blood were the most altered in AD. They reported 5 CSF core biomarkers associated with AD [11]. Subsequently, Bastos et al. compiled data from 18 proteomic studies to obtain 309 proteins expressed differentially in CSF obtained from AD patients vs. controls [12]. The most recent CSF proteomic analysis, which appeared while we were finishing our study, included 29 studies, of which 25 specifically investigated differences between $\mathrm{AD}$ and controls, and reported that 478 proteins exhibited different levels in AD compared to controls [13]. This analysis includes most of the proteins that have been shown to differ between AD and controls. However, these data do not consider the statistical relevance of hits. Furthermore, none of the indicated reviews analyze all tryptic peptides on the basis of specific up- or down- regulation in AD. Therefore, the accuracy of the correlation of these potential protein biomarkers, and their specific tryptic peptides, with actual AD pathology remains unclear.

In the current review, by using various bioinformatics resources, we have generated a consistent data output which compiles protein changes presented in widely different formats in the various original independent studies. First, we searched the literature for unbiased CSF explorative proteomics studies that investigate $\mathrm{AD}$ and compiled data from 47 independent published studies, which considerably increases the number of studies collected so far, thereby expanding to 601 the total number of proteins identified in proteomic studies of CSF from AD patient samples. Additionally, we classified those studies as either descriptive or supported by quantitative data in order to exclusively extract those proteins whose levels were significantly altered in each of the studies. Thus, we have generated a panel of specific proteins that consistently appear in these studies to be over- or underrepresented; and we detail their frequencies. Finally, as an important part of our study, we present a well-characterized and validated peptide analysis of all MS-data obtained from the proteins that show consistent changes (up- or down- regulation). A deep study of this novel AD peptide database, containing more than 3000 tryptic peptides, has led us to unveil a new panel consisting of the most commonly identified peptides in AD CSF, including the peptide direction change in each independent study; significance; and abundance in these clinical cohorts.

\section{Methods}

Data sources and search strategy

We searched MEDLINE (via PubMed) to December 2019. The keywords to perform the advanced search were "cerebrospinal fluid" and/or "CSF", "proteomics", "peptidomics" and "Alzheimer's". We also searched for additional terms such as "biomarkers" and for specific proteomic approaches (i.e. LC-MS/MS) (Fig. 1).

\section{Inclusion criteria and construction of the database}

To strengthen the study, we included only studies that identified more than one protein as an $\mathrm{AD}$ biomarker in CSF, removing 8 studies that focused on only one protein (see Fig. 1) or those that only provided qualitative information $(n=7)$. We also removed those studies that involved only $\mathrm{A} \beta$ and tau variants/isoforms $(\mathrm{n}=13)$; studies focused exclusively on post-translational modifications (PTM) $(\mathrm{n}=4)$; and others that, although containing the search parameters within the text, did not actually perform experimental proteomics research on CSF (for example, in plasma samples) $(\mathrm{n}=27)$ (Fig. 1).

Neuropsychological criteria for the definition of diagnostic groups were heterogeneous (Table 1). Baseline characteristics to define healthy controls according to cognitive criteria were: $C D R=0$, no neuropsychological deficits and/or not reaching mild cognitive impairment (MCI) criteria; score $\geq 23$ on Montreal Cognitive Assessment; MMSE score of 30; and asymptomatic NCs, mutation non-carriers. Baseline criteria to define $\mathrm{AD}$ were the presence of self-reported cognitive complaints; cognitive criteria were $C D R \geq 1$; score $<23$ on the Montreal Cognitive Assessment; subjects who met criteria for probable 


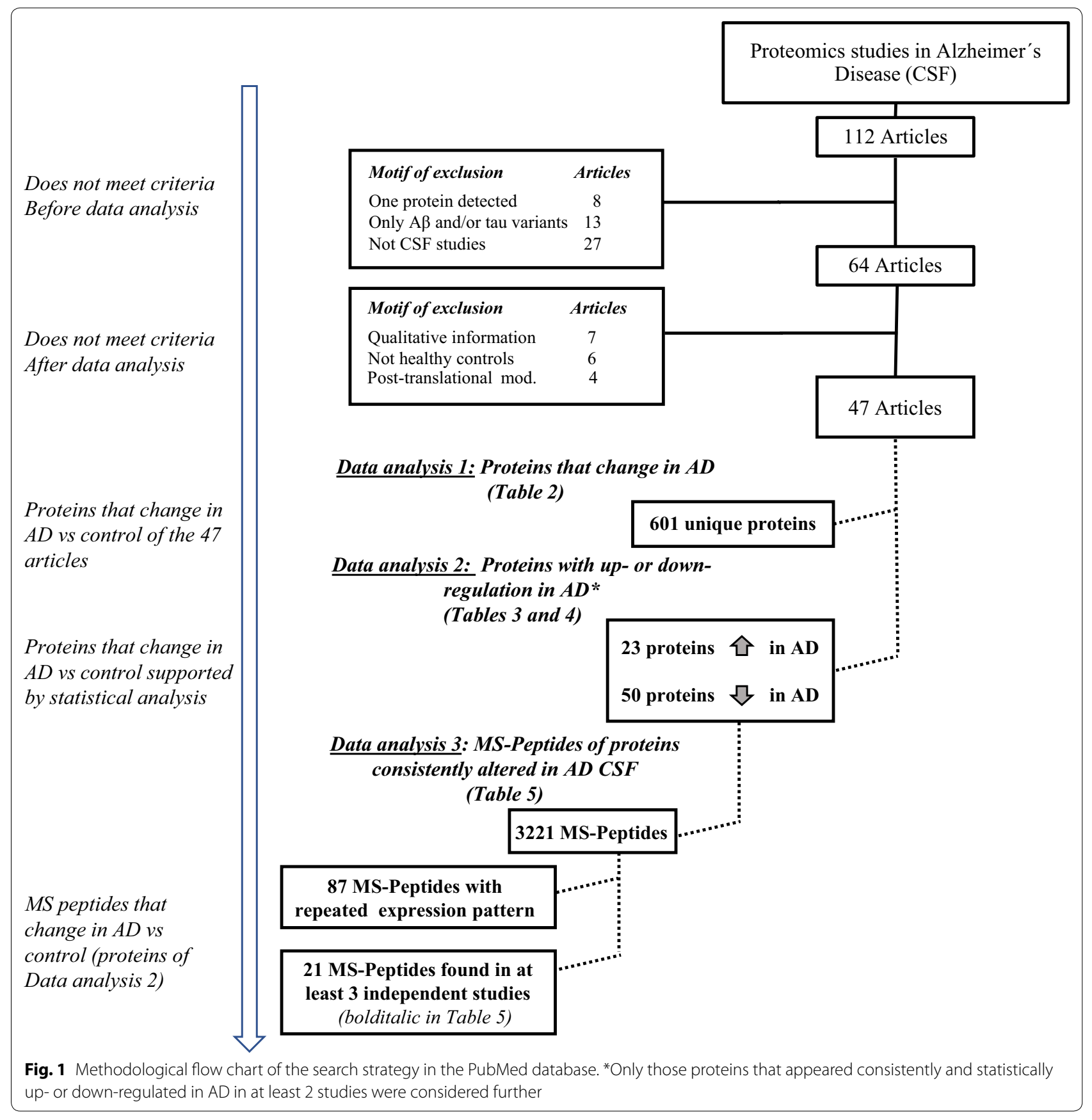

AD dementia based on NIA-AA criteria; and familial Alzheimer disease (FAD) mutation carriers (MCs). In both control and AD groups, 23 out of the 47 studies confirmed an AD diagnosis using the CSF biomarkers A $\beta 42$, T-tau and/or P-tau, and provided clinical evaluations that included the following: detailed informantbased history, assessment of medical records, medical history, family history, physical and neurologic examination, routine lab tests, brain CT or MRI, brain imaging neurological and cognitive examinations. Additional details are shown in Table 1. Thus, we have not included studies that contain the following: categories of pre-MCI individuals or subjective memory complaints (SMC); articles comparing Alzheimer's disease proteins with Parkinson's disease proteins; articles discussing protein differences between younger and older subjects; and articles that studied proteins before and after a specific treatment $(n=6)$. 
Pedrero-Prieto et al. Clin Proteom ～(2020) 17:21

Page 4 of 24

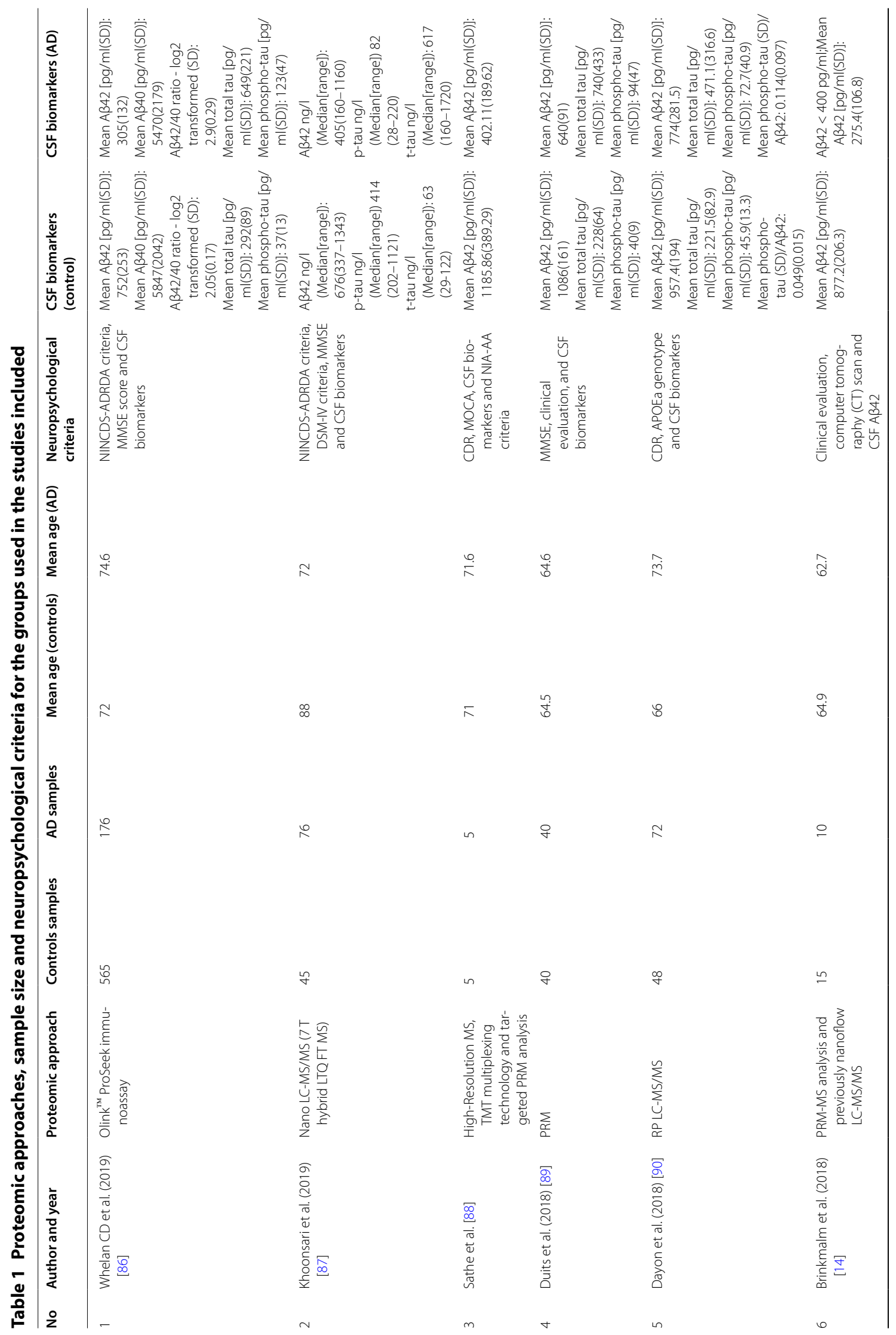


Pedrero-Prieto et al. Clin Proteom ～(2020) 17:21

Page 5 of 24

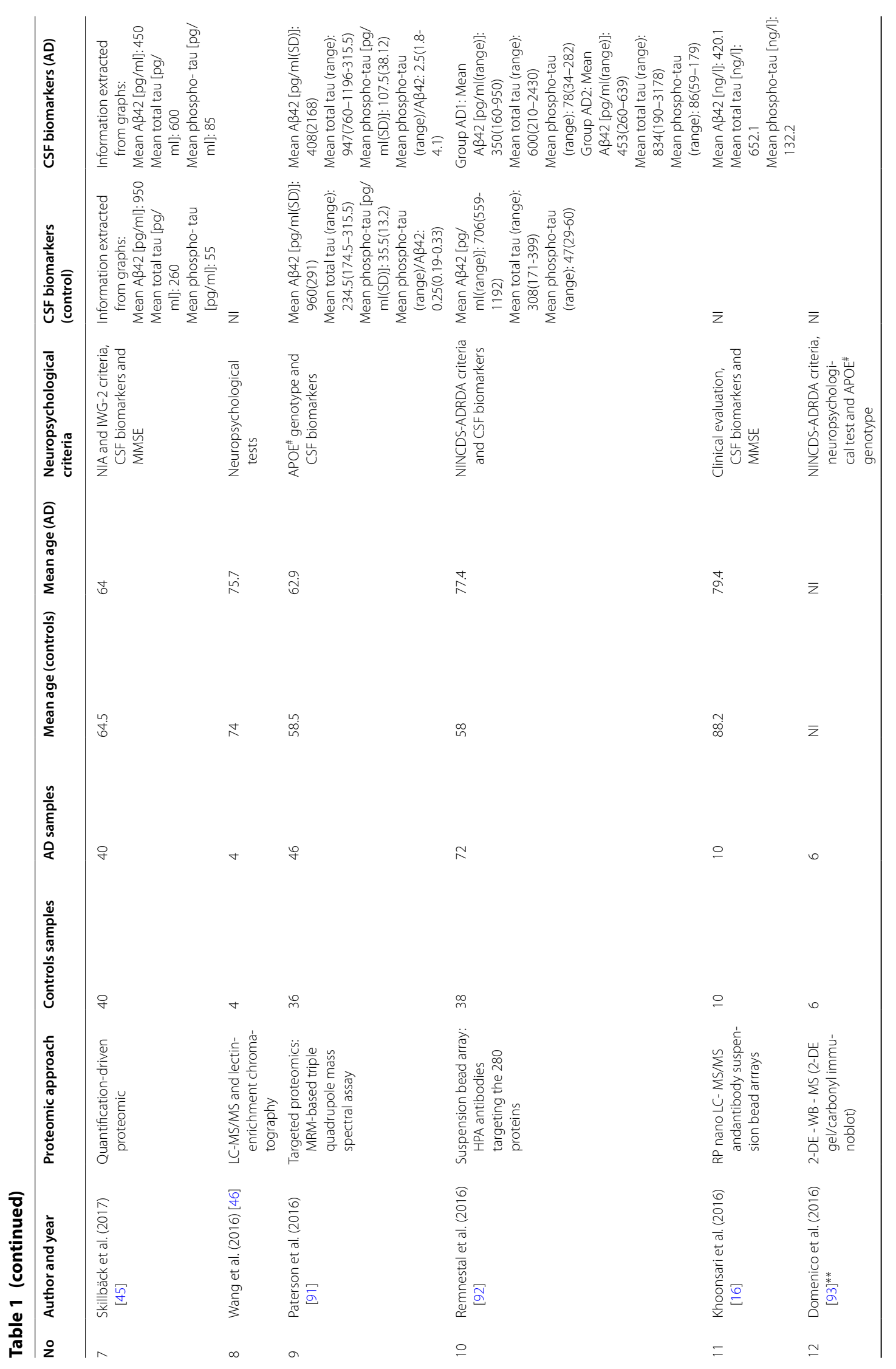




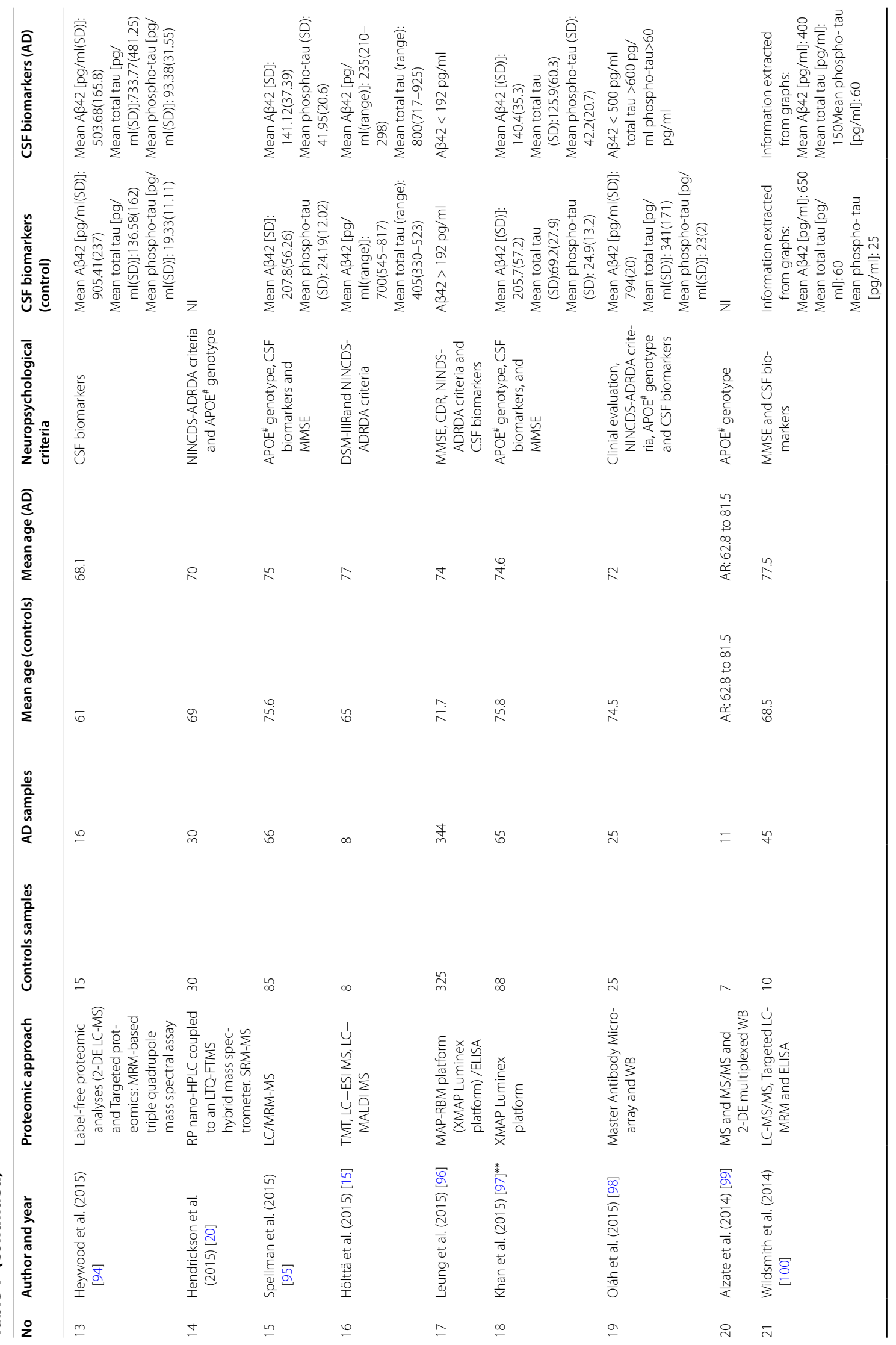




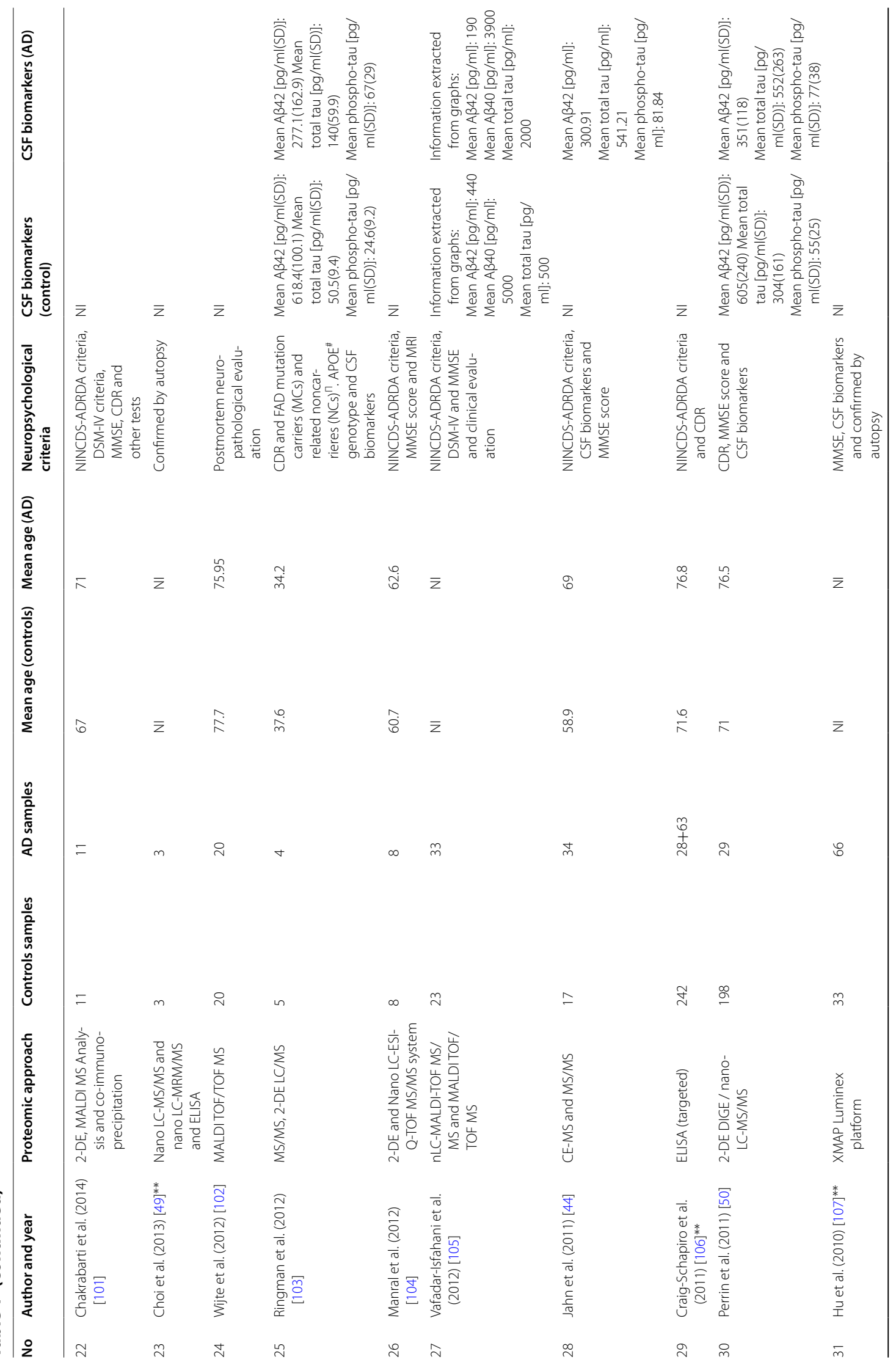




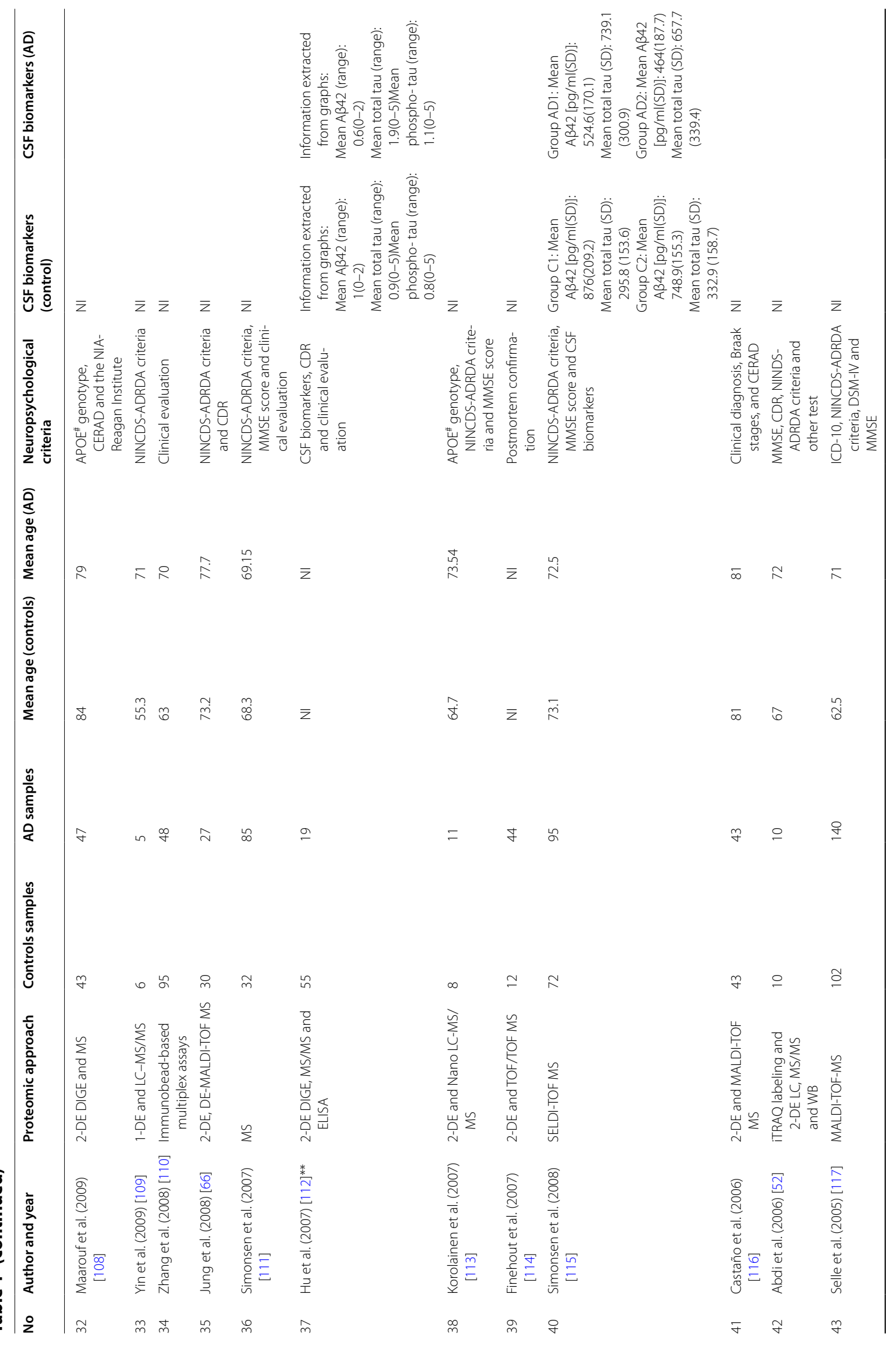




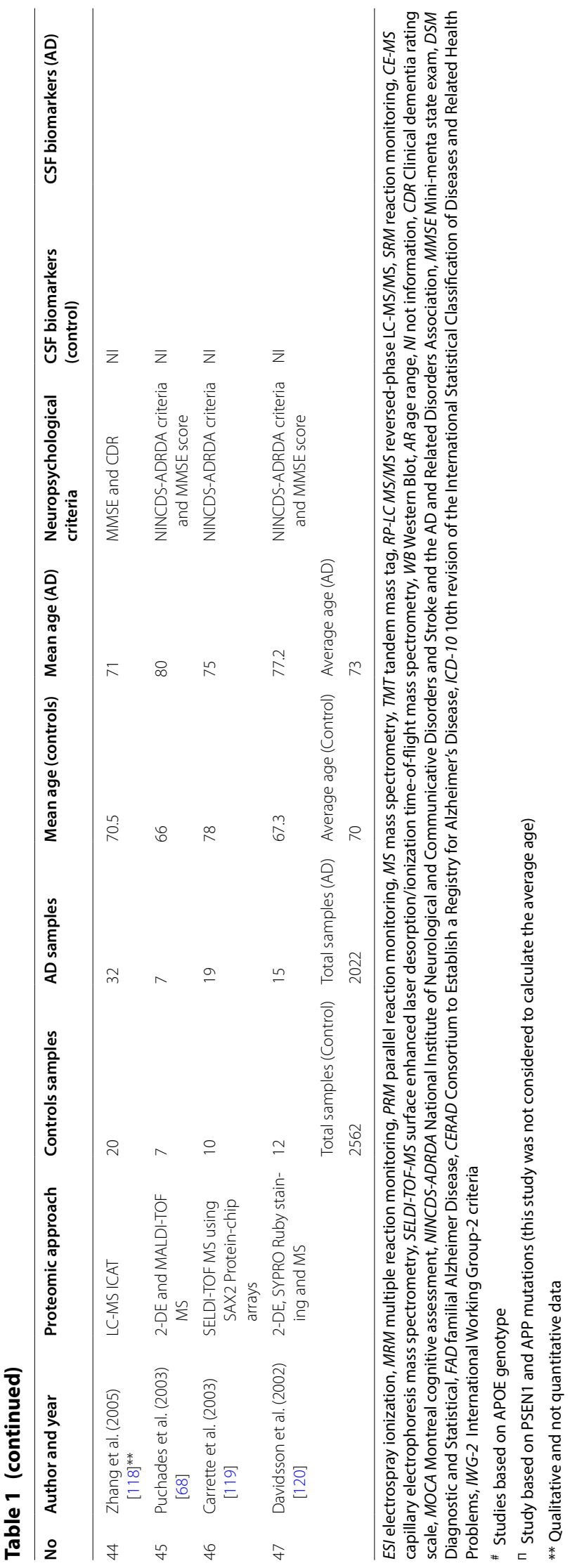


We examined both tables and information included in the main texts, as well as associated supplemental data, to extract information on protein and peptide sequences that were found to be altered in the CSF of AD samples. However, we included in our analysis only those articles that provided statistics for their results by showing significant differences between control and AD groups through numerous statistical methods such as the nonparametric Mann-Whitney U and Kruskal-Wallis tests, which were the most common statistical approaches among the different studies [14-16]. To solve the problem of heterogeneity in the annotation databases used in the various studies, we made all protein names consistent with the Uniprot database (https://www.uniprot.org) by filtering them through Ingenuity Pathway Analysis (IPA, http://www.ingenuity.com) and DAVID bioinformatics resources (http://david.abcc.ncifcrf.gov.), which enabled us to obtain the Entrez Gene ID of all proteins. To do this, it has been necessary to remove "hypothetical proteins", "unidentified proteins", "IgG light chain" "IgG heavy chain" and "predicted protein". Variants of amyloid- $\beta$ and tau, the focus of several reviews $[10,17]$ were not included. Of note, the FLJ00385 protein and all proteins depicted with $\Delta$ were not recognized by DAVID bioinformatics resources.

\section{Data mining}

We included in our analysis exclusively those studies which contained quantitative protein information, according to each study-specific cut-off point with a given statistical significance. The protein database, filtered as described above, was first analyzed to identify the unique proteins that change between $\mathrm{AD}$ and control samples. To analyze all proteins, we extracted related information based on different annotation aspects/terms which was inconsistent in the different studies. For example, Apolipoprotein J, APOJ, APO-J, CLUS_HUMAN, P10909, and TRPM-2 all are referred to Clusterin.

After generating a table containing all proteins that exhibit changes in AD (Additional file 1: Table S1), we calculated the number of articles that identify each specific protein and we further considered those proteins that appeared in 2 or more studies to generate a table that indicated whether they were found to increase or decrease in the context of AD.

An important part of our study consisted in the direct analysis of all MS-data to generate a database of all peptides corresponding to proteins with consistent changes (up- or down- regulation). This database includes all peptide sequences extracted from the proteins mentioned above, the observed peptide mass weight $(\mathrm{Da})$, the significance difference statistics, the ratio of $\mathrm{AD} /$ Control or fold-change, and the direction change in each article. It should be noted that the significance of certain peptide changes had not been included in all studies, and so we independently calculated this parameter from raw data using paired t-tests. In addition, the peptide masses were calculated using the $\mathrm{pl} / \mathrm{Mw}$ tool (https://web.expasy.org/ compute_pi/). We considered only those peptides that appeared at least in two independent studies and analyzed whether their changes were supported by statistical analysis; and those observed in 3 or more independent studies were considered for discussion purposes as the most consistently observed in the context of AD.

\section{Pathway analysis}

Pathway, network and upstream regulator analysis were generated through the use of IPA (QIAGEN Inc., https ://www.qiagenbio-infor matics.com/products/ingen uity-pathway-analysis) with the proteins obtained in the current study, taking into consideration whether they increased or decreased in the context of AD. The threshold for the top canonical pathways was increased to ${ }^{-}-$ Log (p value) 4.5, and only the most relevant network of proteins was considered. Upstream regulators were also investigated, not considering non-endogenous chemical drugs and toxicants. A bias correction of the z-score was performed and activation z-scores below 2 were not further considered in order to reduce artifactual results.

\section{Risk of bias assessment}

We have combined all of the statistical studies for comparative purposes, although the varying degrees of statistical significance intrinsic to the different proteomics and peptidomics approaches must be considered. Although in this study four independent investigators conducted literature searches to identify all possible protein data, we encountered difficulties in extracting the information within several articles, as the annotation datasets used differed between articles, and the statistical approaches were sometimes not clearly described. To allow the reader access to the original extracted information of proteins, we have included Additional file 1: Table S1.

As for the peptide database, it is important to note that only 17 articles reported actual peptide sequences; thus, this peptide analysis constitutes a different analysis than the one carried out with proteins.

\section{Results}

Our initial bibliographic screens support the idea that, among the different pathologies that affect the brain, $\mathrm{AD}$ is likely the most investigated from a proteomics point of view, with a total of 112 proteomics-related articles (Fig. 1). In order to generate a reliable database with only those studies that contain statistically significant proteomic data between AD and control samples- controls 
Table 2 Proteins that show differences between AD and control groups across independent studies

\begin{tabular}{|c|c|}
\hline $\begin{array}{l}\text { Number } \\
\text { of articles }\end{array}$ & Gene (Protein) \\
\hline 18 & APOE (APOE) \\
\hline 15 & VGF (VGF) \\
\hline 14 & $\operatorname{TTR}(\mathrm{TTHY})^{\$}$ \\
\hline 11 & CHGA $(\mathrm{CMGA})^{\$}, \mathrm{CST} 3(\mathrm{CYTC})^{\$}$ \\
\hline 10 & SERPINA1 (A1AT), APOA1 (APOA1) \\
\hline 9 & C4 (CO4) $)^{\$}, C L U(C L U S)^{\$}$, SPP1 (OSTP) $)^{\$}$, PCSK1N (PCSK1N) \\
\hline 8 & $\mathrm{C} 3(\mathrm{CO} 3)^{5}$ \\
\hline 7 & PTGDS (PTGDS) , B2M (B2MG), GC (VTDB) \\
\hline 6 & ALB (ALBU) $)^{\$}, A 2 M(A 2 M G)^{\$}, A P O H(A P O H) \$, C H I 3 L 1$ (CH3L1), NPTX1 (NPTX1), NPTXR (NPTXR), SCG2 (SCG2), RBP4 (RET4) \\
\hline 5 & 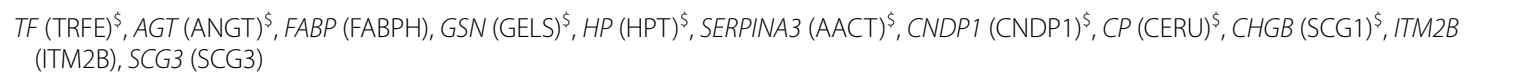 \\
\hline 4 & $\begin{array}{l}\text { A1BG (A1BG) , FGB (FIBB), PLG (PLMN) , NRXN1 (NRX1A), MDH1 (MDHC), APOD (APOD) , CFB (CFAB) , HPX (HEMO) }, \text { IGFBP2 (IBP2), RETN } \\
\text { (RETN), DAG1 (DAG1), APP (A4), FGA (FIBA), SPRC (SPARC), SPON1 (SPON1), GOT1 (AATC), APLP2 (APLP2), SCG5 (7B2), CLSTN1 (CSTN1), } \\
\text { MCAM (MUC18), SERPINF1 (PEDF) }\end{array}$ \\
\hline 3 & $\begin{array}{l}\text { AMBP (AMBP), ITIH1 (ITIH1), LRG1 (A2GL), MT3 (MT3), NEGR1 (NEGR1), RNASE1 (RNASE1), SORT1 (SORT), APOC1 (APOC1), ALDOA (ALDOA), C2 } \\
\text { (CO2), PKM (KPYM), AFM (AFAM), APOA2 (APOA2) , CLEC3B (TETN), CFD (CFAD), HGF (HGF), PPY (PAHO), PSAP (SAP), VEGF (Q9UNS8), CNTN1 } \\
\text { (CNTN1), NCAM1 (NCAM1), SPARCL1 (SPRL1) , CXCL16 (CXL16), SPOCK1 (TICN1), VEGFA (VEGFA), EFEMP1 (FBLN3), BASP1 (BASP1), KNG1 } \\
\text { (KNG1)\$, NSG1 (NSG1), PRNP (PRIO), SERPINC1 (ANT3) , SMOC1 (SMOC1), SOD1 (SODC), APLP1 (APLP1) }\end{array}$ \\
\hline 2 & 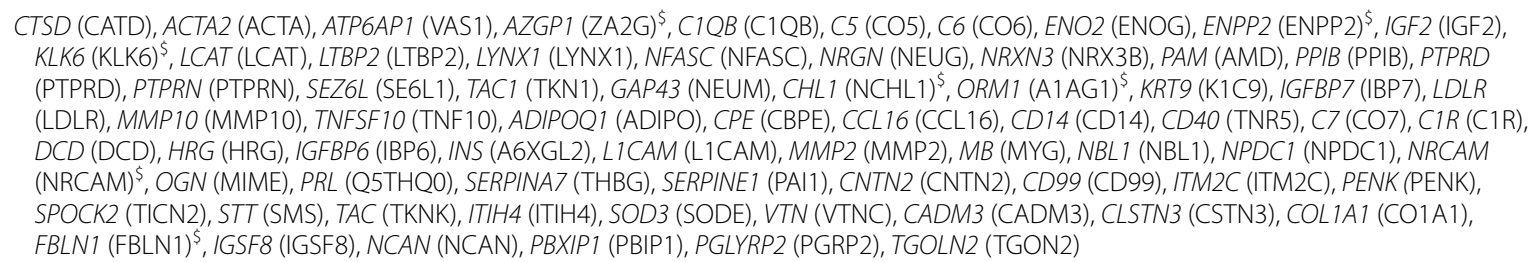 \\
\hline
\end{tabular}

The number of studies which detected these changes is included. \$ proteins which are abundant in CSF of healthy individuals (Schilde et al. 2018)

being exclusively healthy individuals (see Table 1 for information regarding neurophysiological criteria), we did not consider studies/data specific to MCI. After this screening, 47 articles were included in our analyses (Fig. 1). From these 47 articles, we generated a database that contains proteomic studies from a total of 2022 AD patients with a mean age of 73 years and a total of 2562 samples of healthy individuals with a mean age of 70 years (Table 1). Annotation databases used in the different articles to identify the proteins differed; therefore, a refinement of the database was needed to generate similar data outputs using IPA and DAVID bioinformatic resources. Information on the meaning of the abbreviations used for each protein and article (numbered from 1 to 47) is shown in Additional file 1: Table S1.

\section{Analysis of the proteins that were found to change in AD vs control samples}

Additional file 2: Table S2 shows information related to the proteins identified as changing in $\mathrm{AD}$, along with the number of articles that found changes in a particular protein. After matching the proteomic information between the different articles, a total of 601 unique proteins were identified (Additional file 2: Table S2). The proteins that appeared in at least 2 proteomic studies are shown in Table 2 (162 proteins). The most recurrent proteins were Apolipoprotein E (APOE), Nerve growth factor inducible (VGF) and Transthyretin (TTHY), being identified in 18,15 and 14 independent proteomics studies, respectively (Table 2). In order to provide information on the faddabundance of each protein, the 50 most abundant proteins in the CSF of healthy individuals, according to published sources [18], are designated with $\$$ in Tables 2, 3 and 4.

We found that, of the proteins that were identified in more than one study, 63 proteins appeared both as increased and decreased in different proteomic studies and therefore were considered as inconsistent (Additional file 3: Table S3). On the other hand, we identified 23 proteins which were increased (Table 3 ), and 50 proteins decreased (Table 4) in AD samples in at least in 2 independent studies. Of these, a set of 27 proteins, indicated in bolditalic in Tables 3 and 4, represents the most consistent findings across the proteomic literature, being 
Table 3 Proteins increased in AD CSF proteomic studies

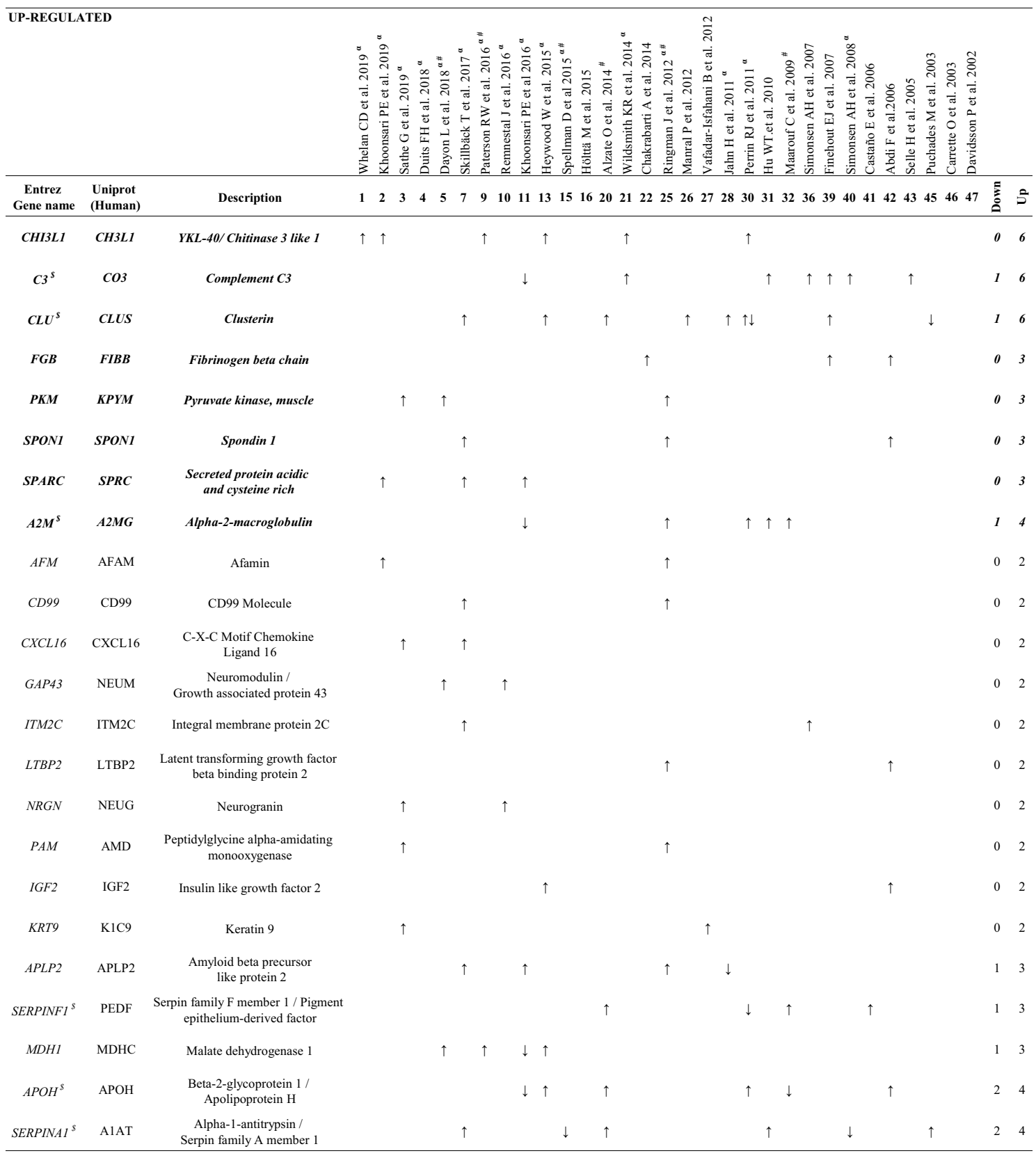

Proteins with the same pattern of expression (toward the same direction) at least in 2 or 3 (bolditalic proteins) independent studies

$\$$ Proteins abundant in CSF of healthy individuals (Schilde et al. 2018)

a Studies that provide $A \beta$ and Tau contents in CSF

\# APOE genotype to diagnose AD

observed with the same pattern of expression at least in 3 independent studies. It is interesting to point out that although some of the studies included in our analysis used depletion kits prior to proteomics, from all possible proteins affected by the use of these kits, only 2 , Albumin (ALB) and Fibrinogen beta chain (FIBB), were among the proteins detected in our study.
A pathway analysis of the subset of proteins exhibiting consistent changes (Tables 3 and 4) was performed using IPA, taking into account the significance of their increase or decrease. LRX/RXR activation appeared as the pathway with the most members of the study along with a significant negative z-score (Fig. 2a). Additionally, one major interacting network was identified, related to cell-to-cell 
Table 4 Proteins decreased in AD CSF proteomic studies

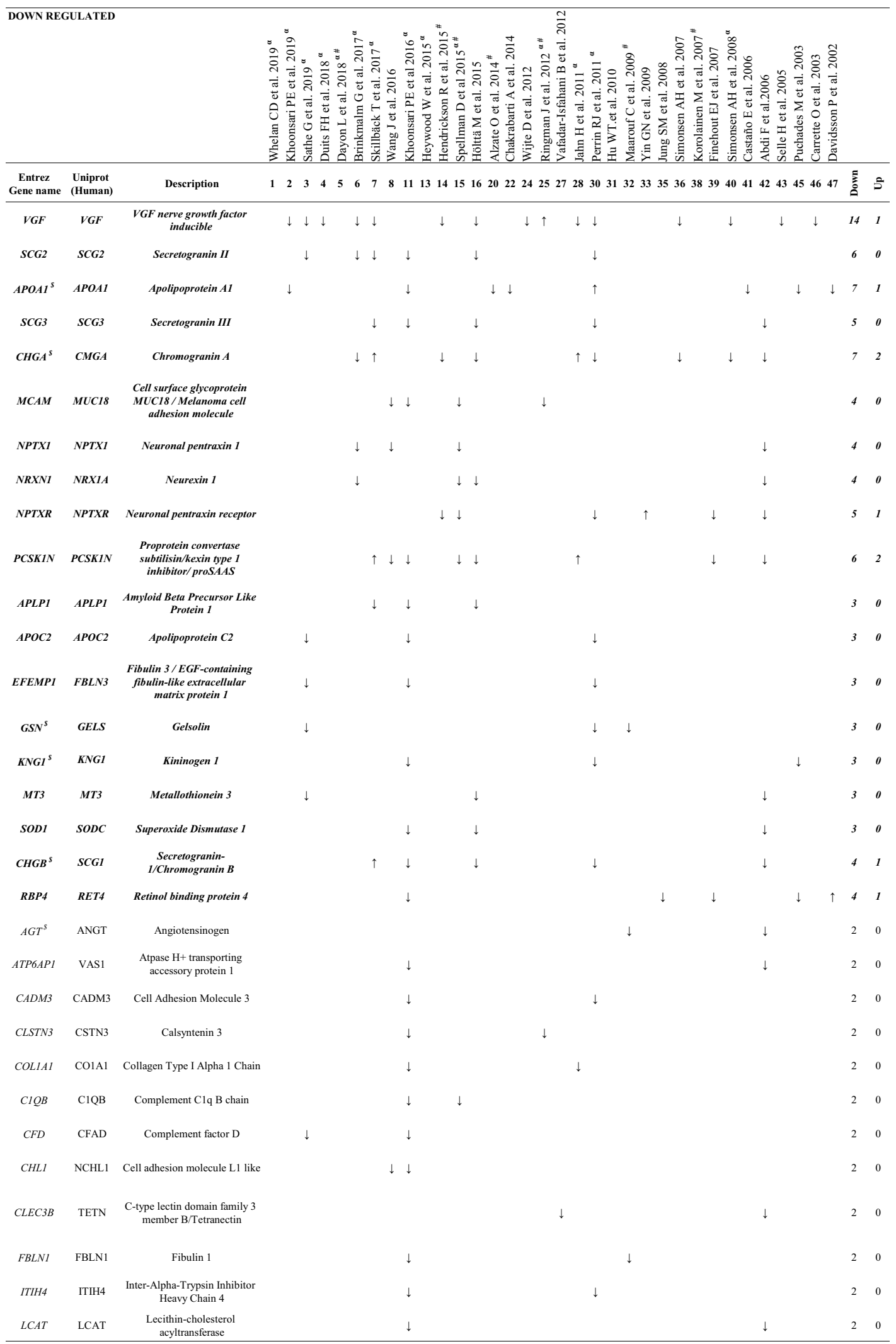


Table 4 (continued)

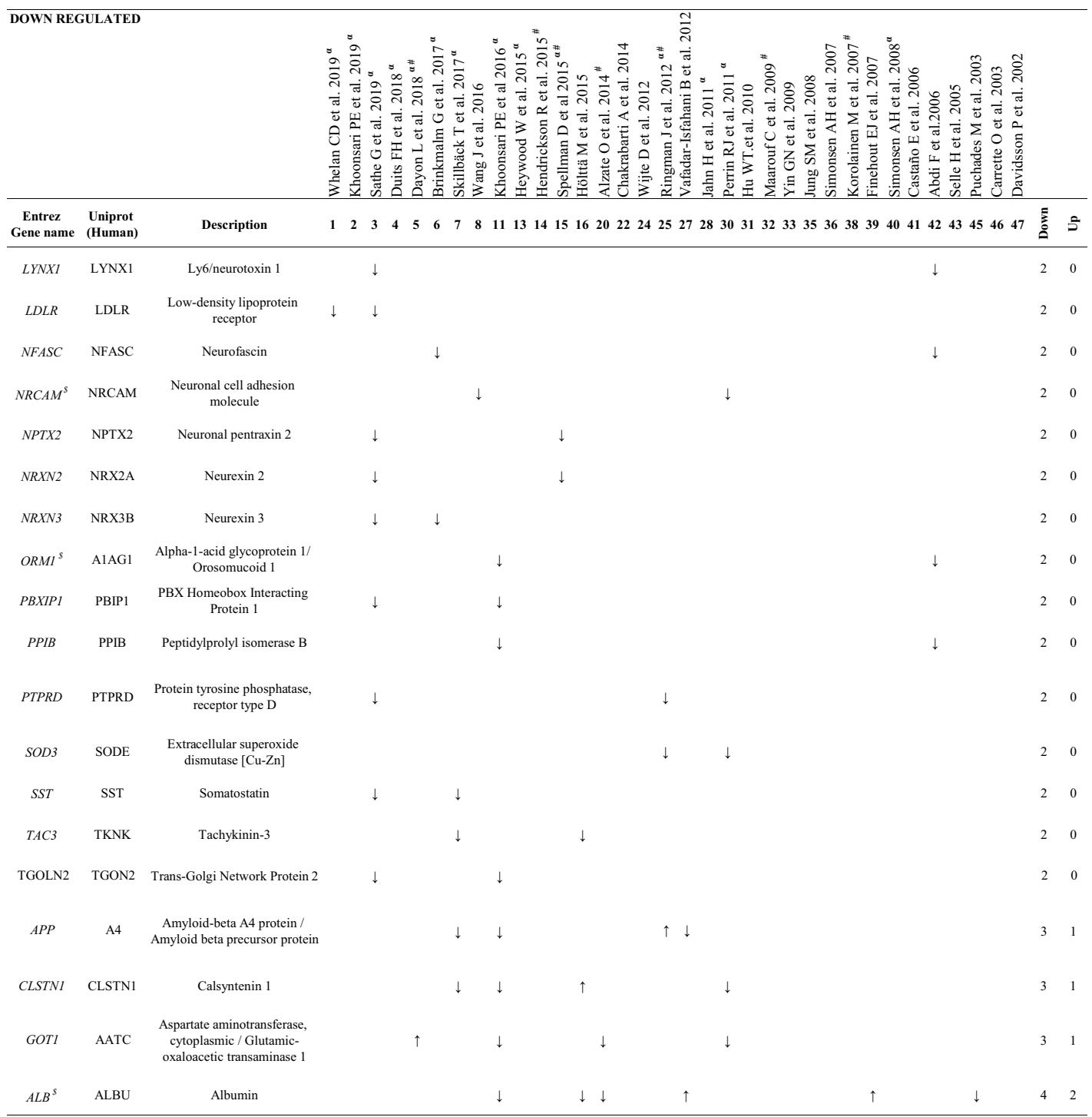

Proteins with the same pattern of expression (toward the same direction) at least in 2 or 3 (bolditalic proteins) independent studies

$\$$ Proteins abundant in CSF of healthy individuals (Schilde et al. 2018)

a Studies that provide $A \beta$ and Tau contents in CSF

\# APOE genotype to diagnose AD

signalling: cellular assembly and organization-nervous system development and function (Fig. 2b). Our IPA analysis revealed that the transcription factor NFE2L2/ NRF2 (nuclear factor, erythroid 2-like 2; predicted to be inhibited) and the Serine/Threonine Kinase 11 (STK11 kinase; predicted to be activated) were the most consistent potential upstream regulators (both $\mathrm{z}$-scores $>2$; $\mathrm{P}$ value $<0.0001$; Fig. 2c).
Analysis of the tryptic peptides of the proteins that change in $A D$ vs control samples

In order to identify changes at the peptide level, we performed a direct analysis of MS-data of the 27 proteins consistently recognized as altered in AD. Information regarding peptide masses of these proteins was available in 17 studies. With the information extracted from these articles we were able to generate a database with 3221 peptide sequences (Additional file 4: Table S4). Further analysis of this database revealed that 87 peptides [Table 5 and Additional file 6: Figure S1 (sequences 
in bolditalic and in red)], which correspond to a total of 13 proteins (2 proteins increased and 11 decreased in $\mathrm{AD})$ maintained a direction change consistent with that observed by proteomics in relation to the AD pathology (Table 5). Other peptides from these proteins showed inconsistent distribution across the different studies (Additional file 5: Table S5). On the other hand, 21 peptides (Table 5 (bolditalic) and Additional file 6 Figure S1 (underlined)] were found in at least 3 independent studies. These peptides correspond to Chitinase 3 like 1 (CH3L1, 2 peptides), VGF (9 peptides), Secretogranin-2 (SCG2, 1 peptide), ProSAAS (PCSKN1, 6 peptides), EGF-containing fibulin-like extracellular matrix protein 1 (FBLN3, 1 peptide), and Apolipoprotein C2 (APOC2, 2 peptides). Interestingly, $\mathrm{CH} 3 \mathrm{~L} 1$ was the only protein with no inconsistency in all identified peptides, since all were found to increase in AD (Table 5).

\section{Discussion}

In this comparative analysis we have compiled data from proteomic studies performed on human CSF samples obtained from $\mathrm{AD}$ and healthy individuals in order to construct a database of proteins and peptides that constitute the most reliable CSF biomarkers associated with an $\mathrm{AD}$ diagnosis. When comparing our hit proteins with the recently published CSF proteomics analysis performed by Wesenhagen et al., numerous differences are evident. An important distinction may be the use of different inclusion criteria in the two analyses. In order to generate a more accurate and reliable database, we exclusively took into consideration those proteins which were shown to be statistically significantly different between $\mathrm{AD}$ and control samples, according to each study-specific cut-off point. Therefore, our analysis relies exclusively on the basis of significant data, including hit distribution, direction change and significance, which could account for the discrepancies observed with Wesenhagen et al. We have also generated a novel database of peptides according to the proteomic findings that reveals the most consistently altered tryptic peptide biomarkers of $\mathrm{AD}$ within a given protein.

We initially identified APOE, TTHY, Osteopontin (OSTP) and Cystatin-C (CYTC) which are among the most abundant proteins in normal CSF [18] as the protein species whose levels change the most often in the context of AD. However, these 5 proteins appear both as increased and decreased in different proteomic studies. Although the number of studies included in Wesenhagen analysis was lower than ours, these findings are in agreement with their study [13], and prompts us to

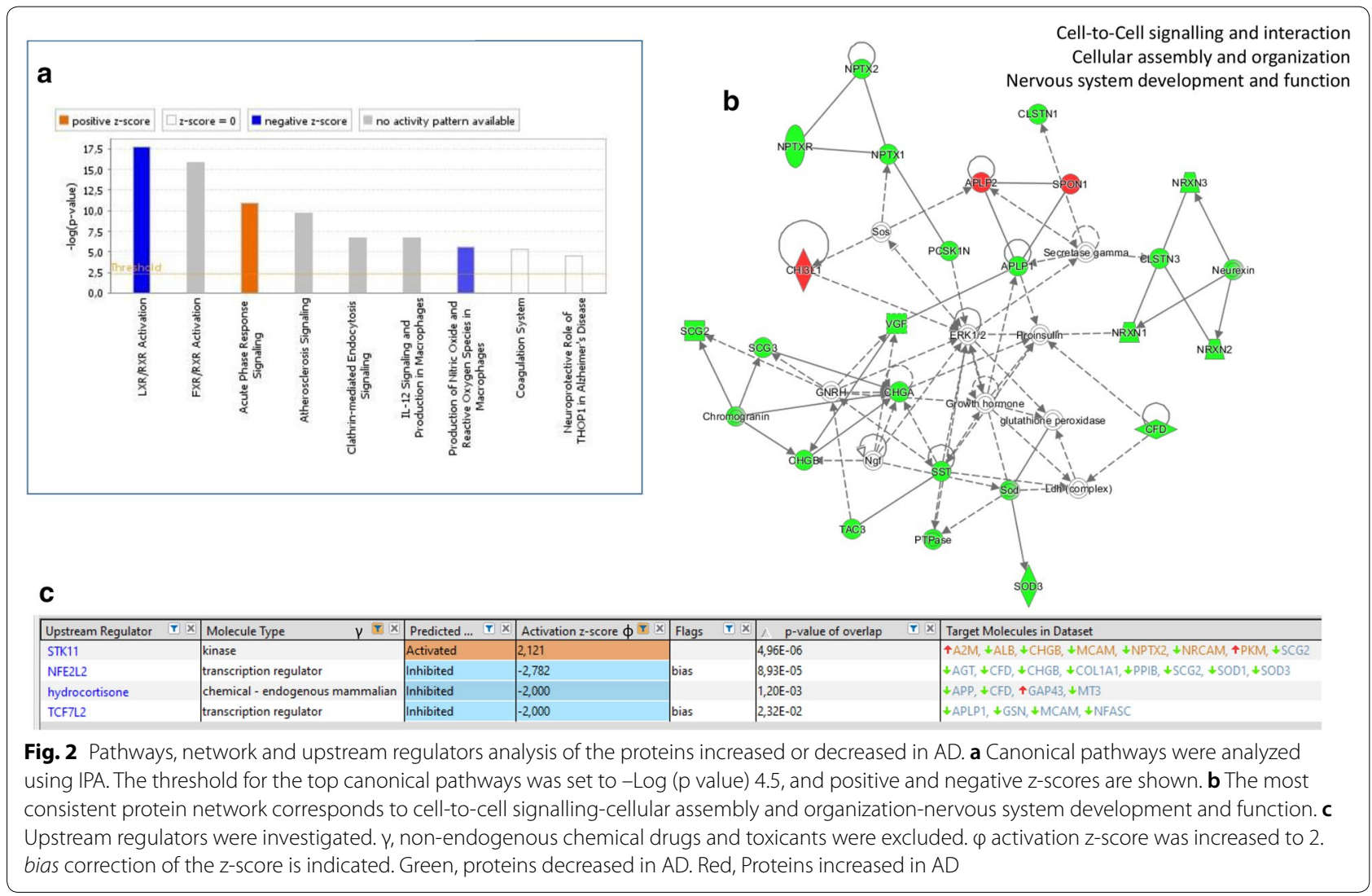


Table 5 Peptide sequences from the proteins altered in AD CSF proteomic studies

\begin{tabular}{|c|c|c|c|c|c|c|c|c|c|c|c|c|c|c|c|c|c|c|c|}
\hline & & 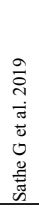 & 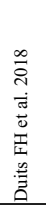 & 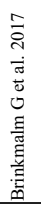 & 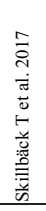 & 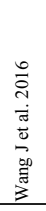 & 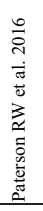 & 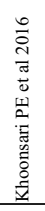 & 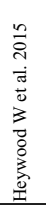 & 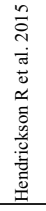 & 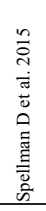 & 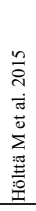 & 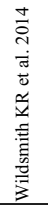 & 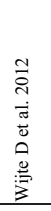 & 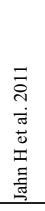 & 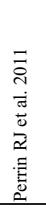 & & & \\
\hline & & 3 & 4 & 6 & 7 & 8 & 9 & 11 & 13 & 14 & 15 & 16 & 21 & 24 & 28 & 30 & Down & Up & $\begin{array}{c}\text { Direction of } \\
\text { change }\end{array}$ \\
\hline \multirow{3}{*}{ CH3L1 } & LVMGIPTFGR & & & & & & $\uparrow$ & & $\uparrow$ & & & & & & & $\uparrow^{*}$ & 0 & 3 & Increase \\
\hline & TLLSVGGWNFGSQR & & & & & & $\uparrow$ & & $\uparrow$ & & & & & & & $\uparrow^{*}$ & 0 & 3 & Increase \\
\hline & EAGTLAYYEICDFLR & & & & & & & & & & & & $\uparrow^{*}$ & & & $\uparrow^{*}$ & 0 & 2 & Increase \\
\hline \multirow{3}{*}{ CLUS } & SHTSDSDVPSGVTEV & & & & $\uparrow$ & & & & & & & & & & $\uparrow$ & & 0 & 2 & Increase \\
\hline & FDSDPITVTVPVEVSRKNPK & & & & $\uparrow$ & & & & & & & & & & $\uparrow$ & & 0 & 2 & Increase \\
\hline & DQTVSDNELQEMSNQGSKYVNKE & & & & $\uparrow^{*}$ & & & & & & & & & & $\uparrow$ & & 0 & 2 & Increase \\
\hline \multirow{24}{*}{ VGF } & NSEPQDEGELFQGVDPR & $\downarrow^{*}$ & $\downarrow$ & $\downarrow^{*}$ & & & & & & $\downarrow^{*}$ & & & & & & & 4 & 0 & Decrease \\
\hline & APPEPVPPPRAAPAPTHV & & & & $\downarrow^{*}$ & & & & & & & $\downarrow$ & & & $\downarrow$ & & 3 & 0 & Decrease \\
\hline & GRPEAQPPPLSSEHKEPVAGDAVPGPKDGSAPEV & & & & $\downarrow \downarrow^{*}$ & & & & & & & $\downarrow$ & & & $\downarrow^{*}$ & & 3 & 0 & Decrease \\
\hline & GRPEAQPPPLSSEHKEPVAGDAVPGPKDGSAPEVRGA & & & & $\downarrow \downarrow^{*}$ & & & & & & & $\downarrow$ & & & $\downarrow^{*}$ & & 3 & 0 & Decrease \\
\hline & APPEPVPPPRAAPAPT & & & & $\downarrow$ & & & & & & & $\downarrow$ & & & $\downarrow$ & & 3 & 0 & Decrease \\
\hline & GRPEAQPPPLSSEHKEPVAGDAVPGPKDGSAPE & & & & $\downarrow$ & & & & & & & $\downarrow$ & & & $\downarrow$ & & 3 & 0 & Decrease \\
\hline & AYQGVAAPFPK & $\downarrow$ & $\downarrow$ & $\downarrow^{*}$ & & & & & & & & & & & & & 3 & 0 & Decrease \\
\hline & APPGRPEAQPPPLSSEHKEPVAGDAVPGPKDGSAPEV & & & & & & & & & & & $\downarrow$ & & $\downarrow$ & $\downarrow$ & & 3 & 0 & Decrease \\
\hline & AAPAPTHVRSPQPPPPAPAPARDELPD & & & & $\downarrow$ & & & & & & & $\downarrow$ & & & $\downarrow$ & & 3 & 0 & Decrease \\
\hline & KNAPPEPVPPPRAAPAPTHV & & & & $\downarrow$ & & & & & & & $\downarrow$ & & & & & 2 & 0 & Decrease \\
\hline & QAAAQEER & $\downarrow^{*}$ & & & & & & & & & & & & & & $\downarrow$ & 2 & 0 & Decrease \\
\hline & GLQEAAEER & $\downarrow$ & & & & & & & & & & & & & & $\downarrow^{*}$ & 2 & 0 & Decrease \\
\hline & NAPPEPVPPPR & $\downarrow^{*}$ & & & & & & & & & & & & & $\downarrow$ & & 2 & 0 & Decrease \\
\hline & EPVPPPRAAPAPTHV & & & & $\downarrow^{*}$ & & & & & & & $\downarrow$ & & & & & 2 & 0 & Decrease \\
\hline & GGEERVGEEDEEAAEAEAEAEEAERARQNA & & & & $\downarrow$ & & & & & & & $\downarrow$ & & & & & 2 & 0 & Decrease \\
\hline & APPEPVPPP & & & & $\downarrow$ & & & & & & & $\downarrow$ & & & & & 2 & 0 & Decrease \\
\hline & ALAAVLLQALDRPASPPAPSGSQQGPEEEAAEALLTETV & & & & $\downarrow$ & & & & & & & $\downarrow$ & & & & & 2 & 0 & Decrease \\
\hline & VGEEDEEAAEAEAEAEEAER & $\downarrow^{*}$ & & & & & & & & $\downarrow^{*}$ & & & & & & & 2 & 0 & Decrease \\
\hline & NAPPEPVPPPRAAPAPTHVRSPQPPPPAPAPARDELPD & & & & $\downarrow^{*}$ & & & & & & & $\downarrow$ & & & & & 2 & 0 & Decrease \\
\hline & GGEERVGEEDEEAAEAEAEAEEAERA & & & & $\downarrow$ & & & & & & & $\downarrow$ & & & & & 2 & 0 & Decrease \\
\hline & AQEEAEAEERRLQEQEELEN & & & & $\downarrow$ & & & & & & & $\downarrow$ & & & & & 2 & 0 & Decrease \\
\hline & GRPEAQPPPLSSEHKEPVAGDAVPGPKDGSAP & & & & $\downarrow$ & & & & & & & & & & $\downarrow^{*}$ & & 2 & 0 & Decrease \\
\hline & APPEPVPPPR & & & & $\downarrow \uparrow^{*}$ & & & & & & & $\downarrow$ & & & $\downarrow$ & & 3 & 1 & Decrease \\
\hline & NAPPEPVPPPRAAPAPTHV & & & & $\downarrow^{*} \uparrow^{*}$ & & & & & & & $\downarrow$ & & & $\downarrow$ & & 3 & 1 & Decrease \\
\hline \multirow{14}{*}{ SCG2 } & ALEYIENLR & $\downarrow$ & & $\downarrow^{*}$ & & & & $\downarrow$ & & & & & & & & & 3 & 0 & Decrease \\
\hline & GPPKNDDTPN & & & & $\downarrow$ & & & & & & & $\downarrow$ & & & & & 2 & 0 & Decrease \\
\hline & GPPKNDDTPNRQ & & & & $\downarrow$ & & & & & & & $\downarrow$ & & & & & 2 & 0 & Decrease \\
\hline & DSLSEEDWMR & $\downarrow^{*}$ & & & & & & $\downarrow$ & & & & & & & & & 2 & 0 & Decrease \\
\hline & IVEEQYTPQSLATLESVFQELGKLTGPNNQ & & & & $\downarrow$ & & & & & & & $\downarrow$ & & & & & 2 & 0 & Decrease \\
\hline & FPSPEMIR & $\downarrow \downarrow^{*}$ & & & & & & $\downarrow \downarrow$ & & & & & & & & & 2 & 0 & Decrease \\
\hline & VPGQGSSEDDLQEEEQIEQAIK & $\downarrow$ & & & & & & $\uparrow \downarrow$ & & & & & & & & & 2 & 0 & Decrease \\
\hline & IESQTQEEVRDSK & $\downarrow$ & & & & & & $\downarrow$ & & & & & & & & & 2 & 0 & Decrease \\
\hline & RLVNAAGSGR & $\downarrow$ & & & & & & $\downarrow$ & & & & & & & & & 2 & 0 & Decrease \\
\hline & QAENEPQSAPK & $\downarrow$ & & & & & & & & & & & & & & $\downarrow^{*}$ & 2 & 0 & Decrease \\
\hline & GQGSSEDDLQEEEQIEQAIKEHLNQGSSQETDKLAPVS & & & & $\downarrow \downarrow^{*}$ & & & & & & & $\downarrow$ & & & & & 2 & 0 & Decrease \\
\hline & TNEIVEEQYTPQSLATLESVFQELGKLTGP & & & & $\downarrow \downarrow *$ & & & & & & & $\downarrow$ & & & & & 2 & 0 & Decrease \\
\hline & QYWDEDLLMK & $\downarrow$ & & & & & & $\downarrow$ & & & & & & & & & 2 & 0 & Decrease \\
\hline & VLEYLNQEK & $\downarrow$ & & $\downarrow$ & & & & $\uparrow \downarrow$ & & & & & & & & & 3 & 1 & Decrease \\
\hline \multirow{2}{*}{ SCG3 } & ELSAERPLNEQIAEAEEDKI & & & & $\downarrow \downarrow^{*}$ & & & & & & & $\downarrow$ & & & & & 2 & 0 & Decrease \\
\hline & ELSAERPLNEQIAEAEED & & & & $\downarrow \downarrow^{*}$ & & & & & & & $\downarrow$ & & & & & 2 & 0 & Decrease \\
\hline \multirow{5}{*}{ CMGA } & EGQEEEEDNRDSSMK & & & & $\downarrow$ & & & & & & & $\downarrow$ & & & & & 2 & 0 & Decrease \\
\hline & YPGPQAEGDSEGLSQGLVDR & & & $\downarrow$ & & & & & & $\downarrow^{*}$ & & & & & & & 2 & 0 & Decrease \\
\hline & FEDELSEVLENQSSQAELKE & & & & $\downarrow$ & & & & & & & $\downarrow$ & & & & & 2 & 0 & Decrease \\
\hline & GFEDELSEVLENQSSQAELKEAVEEPSSKDVME & & & & $\downarrow$ & & & & & & & $\downarrow$ & & & & & 2 & 0 & Decrease \\
\hline & LEGQEEEEDNRDSSMKLSFRA & & & & $\uparrow \downarrow$ & & & & & & & $\downarrow$ & & & $\downarrow$ & & 3 & 1 & Decrease \\
\hline NPTX1 & LENLEQYSR & & & $\downarrow^{*}$ & & & & & & & $\downarrow$ & & & & & & 2 & 0 & Decrease \\
\hline \multirow{4}{*}{$\begin{array}{l}\text { NPTXR } \\
\end{array}$} & VAELEHGSSAYSPPDAFK & & & & & & & & & $\downarrow$ & & & & & & $\downarrow$ & 2 & 0 & Decrease \\
\hline & ETPAPQVPARRLLPP & & & & $\downarrow$ & $\downarrow$ & & & & & & $\downarrow$ & & & $\downarrow$ & & 4 & 0 & Decrease \\
\hline & TPAPQVPARRLLPP & & & & $\downarrow$ & $\downarrow$ & & & & & & $\downarrow$ & & & & & 3 & 0 & Decrease \\
\hline & SPPLAETG & & & & $\downarrow$ & $\downarrow$ & & & & & & $\downarrow$ & & & & & 3 & 0 & Decrease \\
\hline \multirow[t]{4}{*}{ PCSK1N } & ETPAPQVPA & & & & $\downarrow^{*}$ & $\downarrow$ & & & & & & & & & $\downarrow$ & & 3 & 0 & Decrease \\
\hline & DHDVGSELPPEGVLGA & & & & $\downarrow \uparrow^{*}$ & $\downarrow$ & & & & & & $\downarrow$ & & & $\downarrow$ & & 4 & 1 & Decrease \\
\hline & DHDVGSELPPEGVLG & & & & $\downarrow \uparrow^{*}$ & $\downarrow$ & & & & & & $\downarrow$ & & & $\downarrow$ & & 4 & 1 & Decrease \\
\hline & ETPAPQVPARR & & & & $\downarrow$ & $\downarrow$ & & & & & & & & & & & 2 & 0 & Decrease \\
\hline
\end{tabular}


Table 5 (continued)

\begin{tabular}{|c|c|c|c|c|c|c|c|c|c|c|c|c|c|c|c|c|c|c|c|}
\hline & & 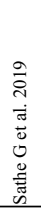 & 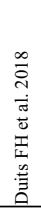 & 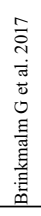 & 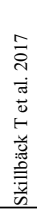 & 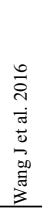 & 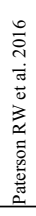 & 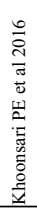 & 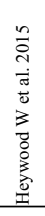 & 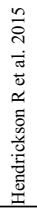 & 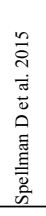 & 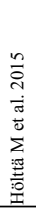 & 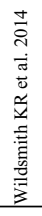 & 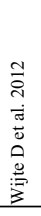 & 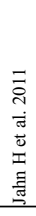 & 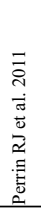 & & & \\
\hline & & 3 & 4 & 6 & 7 & 8 & 9 & 11 & 13 & 14 & 15 & 16 & 21 & 24 & 28 & 30 & Down & Up & $\begin{array}{c}\text { Direction of } \\
\text { change }\end{array}$ \\
\hline \multirow{13}{*}{ APLP1 } & DELAPAGTGVSREA & & & & $\downarrow \downarrow *$ & & & & & & & $\downarrow$ & & & & & 2 & 0 & Decrease \\
\hline & DELAPAGTGVSRE & & & & $\downarrow \downarrow "$ & & & & & & & $\downarrow$ & & & & & 2 & 0 & Decrease \\
\hline & DELAPAGTGVSREAVSGLLIMGAGGGSL & & & & $\downarrow \downarrow$ & & & & & & & $\downarrow$ & & & & & 2 & 0 & Decrease \\
\hline & GFPFHSSEIQ & & & & $\downarrow$ & & & $\downarrow$ & & & & & & & & & 2 & 0 & Decrease \\
\hline & DELAPAGTGVSREAVSGLLIMGAGGGS & & & & $\downarrow$ & & & & & & & $\downarrow$ & & & & & 2 & 0 & Decrease \\
\hline & DELAPAGTGV & & & & $\downarrow$ & & & & & & & $\downarrow$ & & & & & 2 & 0 & Decrease \\
\hline & DELAPAGTGVSREAVSGL & & & & $\downarrow$ & & & & & & & $\downarrow$ & & & & & 2 & 0 & Decrease \\
\hline & DELAPAGTGVSREAVSG & & & & $\downarrow$ & & & & & & & $\downarrow$ & & & & & 2 & 0 & Decrease \\
\hline & ELAPAGTGV & & & & $\downarrow$ & & & & & & & $\downarrow$ & & & & & 2 & 0 & Decrease \\
\hline & DELAPAGTGVSREAVSGLL & & & & $\downarrow$ & & & & & & & $\downarrow$ & & & & & 2 & 0 & Decrease \\
\hline & DELAPAGTGVSREAVSGLLIMGAGGG & & & & $\downarrow$ & & & & & & & $\downarrow$ & & & & & 2 & 0 & Decrease \\
\hline & DELAPAGTGVSREAVSGLLIM & & & & $\downarrow$ & & & & & & & $\downarrow$ & & & & & 2 & 0 & Decrease \\
\hline & SLAGGSPGAAEAPGSAQVAGLCGRLT & & & & $\downarrow$ & & & & & & & $\downarrow$ & & & & & 2 & 0 & Decrease \\
\hline \multirow{3}{*}{ APOC2 } & TYLPAVDEK & $\downarrow^{*}$ & & & & & & $\downarrow$ & & & & & & & & $\downarrow$ & 3 & 0 & Decrease \\
\hline & TAAQNLYEK & $\downarrow^{*}$ & & & & & & $\downarrow$ & & & & & & & & $\downarrow^{*}$ & 3 & 0 & Decrease \\
\hline & ESLSSYWESAK & $\downarrow$ & & & & & & $\uparrow \downarrow$ & & & & & & & & $\downarrow$ & 3 & 1 & Decrease \\
\hline \multirow{6}{*}{ FBLN3 } & QTSPVSAMLVLVK & $\downarrow \downarrow^{*}$ & & & & & & $\downarrow$ & & & & & & & & $\downarrow^{*}$ & 3 & 0 & Decrease \\
\hline & TCQDINECETTNECR & $\downarrow$ & & & & & & $\downarrow$ & & & & & & & & & 2 & 0 & Decrease \\
\hline & NPCQDPYILTPENR & $\downarrow$ & & & & & & $\downarrow$ & & & & & & & & & 2 & 0 & Decrease \\
\hline & LNCEDIDECR & & & & & & & $\downarrow$ & & & & & & & & $\downarrow$ & 2 & 0 & Decrease \\
\hline & SGNENGEFYLR & $\downarrow$ & & & & & & $\downarrow \uparrow$ & & & & & & & & $\downarrow$ & 3 & 1 & Decrease \\
\hline & ADQVCINLR & $\downarrow$ & & & & & & $\downarrow \uparrow$ & & & & & & & & $\downarrow$ & 3 & 1 & Decrease \\
\hline \multirow{2}{*}{ GELS } & AGALNSNDAFVLK & $\downarrow$ & & & & & & & & & & & & & & $\downarrow$ & 2 & 0 & Decrease \\
\hline & TGAQELLR & $\downarrow$ & & & & & & & & & & & & & & $\downarrow$ & 2 & 0 & Decrease \\
\hline \multirow{3}{*}{ SCG1 } & SSQGGSLPSEEkGHPQEESEESN & & & & $\downarrow$ & & & & & & & $\downarrow$ & & & & & 2 & 0 & Decrease \\
\hline & ADQTVLTEDEKKELENLAAMDLELQK & & & & & & & $\downarrow$ & & & & & & & & $\downarrow$ & 2 & 0 & Decrease \\
\hline & GGSLPSEEkGHPQEESEESN & & & & $\downarrow$ & & & & & & & $\downarrow$ & & & & & 2 & 0 & Decrease \\
\hline
\end{tabular}

Peptide sequence with the same pattern of expression (toward the same direction) at least in 2 or 3 (bolditalic proteins) independent studies

* Peptide sequences identified which show changes between AD and control samples supported by statistical analysis

suggest that they cannot be considered as reliable CSF biomarkers of AD. While it is likely that heterogeneity in response direction may reflect irrelevant physiological or environmental factors, it is also interesting to speculate that this heterogeneity reflects unknown endophenotypes in $\mathrm{AD}$. It is also possible that the changes in these 5 proteins provide an indication of the profound general protein dysregulation that occurs during $\mathrm{AD}$ progression. Additionally, our study reveals new information regarding proteins consistently altered in $\mathrm{AD}$, including SPARC (SPRC), Kininogen-1 (KNG1) or Cell surface glycoprotein MUC18 (MUC18), whose role as potential CSF biomarkers for $\mathrm{AD}$ has not been investigated. These proteins are discussed below.

Among the most consistently down- and up-regulated AD proteomic biomarkers, our hit proteins with the highest occurrence are VGF and $\mathrm{CH} 3 \mathrm{~L} 1$, respectively. Both can be considered high quality CSF biomarkers, as they represent abundant proteins which consistently change in the same direction in 14 and $6 \mathrm{AD}$ proteomics studies, respectively. VGF is a member of the granin family of proteins [19] previously proposed as a good marker for AD
$[10,13]$, and a decrease in VGF-derived peptides in $\mathrm{AD}$ has been confirmed using other experimental approaches $[14,20,21]$. Interestingly, the 9 peptides that appear as reliable markers for the VGF down-regulation in $\mathrm{AD}$ correspond to both $\mathrm{N}$ - and $\mathrm{C}$-terminal sequences, suggesting that the synthesis of the precursor protein itself is repressed in $\mathrm{AD}$ and not a specific derived peptide.

The levels of CH3L1, encoded by the CHI3L1 gene, were also found to be increased in all 6 proteomics studies in which it was identified, just as reported by Wesenhagen et al. [22]. We propose that CH3L1, which is expressed in the CNS by microglia and astrocytes, constitutes one of the most interesting potential biomarkers, mainly because its physiological role in brain remains speculative. Increased expression of CH3L1 is found in human brains from pathologically confirmed $\mathrm{AD}$ individuals, implicating $\mathrm{CH} 3 \mathrm{~L} 1$ in the neuroinflammatory response to $A \beta$ deposition [23]. Moreover, 2 independent ELISA studies, conducted to evaluate the role of CH3L1 as a CSF biomarker, have confirmed the observation of increased levels of CH3L1 in AD patients $[24,25]$. Given that CH3L1 has been proposed as a 
common neuroinflammatory biomarker of other neurodegenerative diseases, [26, 27], the fact that 2 peptides (see Table 5) were consistently changed in AD studies assumes increased relevance. Although the presence of these peptides may arise as a consequence of intrinsic properties which render them highly identifiable by mass spectrometry, further characterization of these 2 peptides as $\mathrm{AD}$ biomarkers among other neurodegenerative diseases deserves investigation.

\section{Proteins consistently increased in AD CSF}

In addition to CH3L1, other proteins were observed to increase in CSF samples from AD patients. Among those that stand out due to their consistency within the various studies (bolditalic proteins in Table 3) we found Complement C3 (CO3, 6 studies), Alpha-2-macroglobulin (A2MG, 4 studies), FIBB (3 studies), Pyruvate kinase (KPYM, 3 studies) and Spondin-1 (SPON1, 3 studies). This set of proteins has previously been reported to increase in AD CSF [13]. However, our analysis, which includes only significant data, permits the identification of proteins with consistently increased levels in AD CSF whose potential as reliable AD biomarkers was previously overlooked. For example, Clusterin (CLUS) was found to be increased in AD in 6 out of 7 studies. This chaperone protein is involved in lipid transport and metabolism and is produced and secreted predominantly by astrocytes within the CNS [28]. Various studies of CSF from AD patients, most using an ELISA approach, have proposed a role for CLUS as a potential AD biomarker [reviewed in [24]]; our study now provides additional support for this idea.

Finally, SPARC, also known as Osteonectin, was found to be consistently upregulated in CSF from AD patients (3 studies), which validates its novel utility as a reliable CSF biomarker. In brain, its expression is restricted to microglia and subcortical astrocytes, and a role for SPRC has been suggested in neuroinflammation $[29,30]$. Specifically, high levels of SPRC have been shown in AD brain wherein it colocalizes to $A \beta$ protein depots. It has been proposed that SPRC contributes to cerebral inflammation and subsequent tissue repair [31].

\section{Proteins consistently reduced in AD CSF}

Our analysis of proteins consistently reduced in $A D$ identified 19 proteins representing the most consistent biomarkers (bolditalic proteins in Table 4). With our experimental approach, we identified 3 proteins previously reported by Wesenhagen et al., Neurexin 1A (NRX1A), APOC2 and FBLN3. In our study, NRX1A [and Neurexin-2 (NRX2A) and Neurexin-3-beta (NRX3B) to a lesser degree] appears consistently reduced in AD CSF across all of the 4 independent studies in which it was identified. These brain-specific proteins participate in synapse formation, plasticity and stability [32]. A recently published targeted proteomic study using Selected Reaction Monitoring, which monitors neurexin levels in control and preclinical AD patients, reinforces the data reported here by showing reduced levels of NRX2A and NRX3B in preclinical AD CSF [33]. Overall, the reduced levels of neurexins observed in CSF at the earliest preclinical AD stages support the idea of diminished synaptic density during AD progression. We also observed a downregulation of APOC2 in CSF of AD patients in 3 independent studies, again strengthening the notion that a change in lipid metabolism can be potentially related to cognitive status in AD. Supporting this idea, our study found Apolipoprotein A1 (APOA1) as consistently reduced in AD CSF (7 out of 8 studies). Considering that APOA1 is among the most abundant proteins within human CSF [18], the use of APOA1 as biomarker of AD progression is especially relevant to practical biomarker identification, as its reduction in the context of AD is easily measurable.

Finally, FBLN3 codified by the gene EFEMP1, is a glycoprotein associated with the extracellular matrix which is involved in cell proliferation and migration [34]. Although no direct evidence as to a specific role for FBLN3 in AD has been reported, FBLN3 has recently been described as an amyloidogenic protein [35]. FBLN3 was observed to be consistently downregulated in CSF from $\mathrm{AD}$ patients (3 studies). Interestingly, only one tryptic peptide (QTSPVSAMLVLVK) was observed to be down-regulated in all 3 studies, thus highlighting this peptide as the most relevant hit for the characterization of $\mathrm{AD}$ status.

Together with VGF, the members of the granin family Chromogranin-A (CMGA), Secretogranin-1 (SCG1), SCG2, Secretogranin-3 (SCG3) and PCSK1N were found to be consistently decreased in our study. CMGA has been the most frequently detected granin in proteomic CSF studies (7 studies), and this protein, together with SCG1 (found to be decreased in 4 out of 5 studies) represent the most abundant granins in human CSF. Immunoreactivity for CMGA, SCG1 and SCG2 has been observed in amyloid plaques of post-mortem brains from AD patients [36-39]. Taken together, the proteomic studies gathered in this review support the role of CMGA as a reliable CSF biomarker. It is especially relevant that the most consistent tryptic peptides of all proteins that decrease in AD correspond to granins (VGF, CMGA, SCG1, SCG2 SCG3, and PCSK1N). Their acidic isoelectric point and the presence of multiple dibasic cleavage sites could potentially favor their detection by MS-spectrometry, which might constitute an assay advantage, since a panel of these peptides could be designed as a 
direct tool for a fast spectrometric characterization of AD patients.

The granin family member PCSK1N, known as proSAAS, is a protein produced almost exclusively by neurons and endocrine cells, and was reduced in 6 out of the $8 \mathrm{AD}$ proteomic studies where it was identified. Reduced PCSK1N levels in CSF may be related to increased brain retention of this protein within plaques and other aggregates, as previously observed [40-42]. In agreement with this idea, a recent transcriptomic study [43] found increased PCSK1N expression during $\mathrm{AD}$ progression. Interestingly, among all of the peptides included in our peptidomic study, the proSAAS peptide ETPAPQVPARRLLPP was the most consistent finding and corresponds to the $\mathrm{C}$-terminal sequence known as BigLEN (LETPAPQVPARRLLPP). There is a consistent lack of the $\mathrm{N}$-terminal Leucine on the retrieved peptides $[15,44-46]$ which suggests that this peptide corresponds to a biological fragment of proSAAS in CSF not resulting from tryptic cleavage, emphasizing the importance of this modified BigPEN peptide as a possible direct biomarker of AD in CSF.

Interestingly, both Neuronal pentraxin-1 (NPTX1) and Neuronal pentraxin receptor (NPTXR) showed consistent reduction ( 4 and 4 out of 5 studies, respectively). These proteins have been previously implicated in $\mathrm{AD}$ [47]. Although NPTX1 has been primarily considered as a plasma biomarker [48], the current analysis supports its role as a reliable CSF AD biomarker. As this protein likely constitutes a protein associated with both neuronal degradation and synaptic loss $[49,50]$, future work will be needed to determine the specificity of NPTX1 for AD versus other neurodegenerative diseases. The potential role of the NPTXR as a prognostic biomarker for AD has recently been studied by others $[20,51]$. Begcevic et al., observed that CSF NPTXR levels decrease with the severity of AD [51], thereby supporting the significance of NPTXR as a valuable CSF biomarker for specific stages of $\mathrm{AD}$ progression. It is important to point out that from all proteomic studies included in our analysis, NPTX1 and NPTXR were identified together in 2 studies [52] which reinforces the importance of data-mining efforts to identify and consolidate reliable biomarkers of neurodegeneration.

MUC18, an adhesion molecule encoded by the $M C A M-C D 14$ gene, was consistently reduced in AD CSF in 4 independent proteomic studies. We believe this hit is especially interesting since this protein has not been previously linked to the disease. MUC18 is expressed by a subpopulation of IL-17-secreting CD4+ and CD8 + human T cells (Th17 and Tc17 cells, respectively) [53-55]. Chronic neuroinflammation is a phenomenon commonly observed in AD [56], and various Th cell lineages, including Th1, Th17 and regulatory $\mathrm{T}$ cells, appear to play a complex role in $\mathrm{AD}$-associated neurodegeneration [57-62]. In order to explain the significance of reduced MUC18 levels in AD CSF, we suggest that further study of the role of MUC18 in AD inflammation is important.

The Retinol-binding protein 4 (RBP4), found to be reduced in 4 out of 5 studies, can circulate as an adipokine, and is related to insulin metabolism and retinoic acid signalling, both AD-associated processes [63, 64]. Additionally, RBP4 binds to TTHY, a protein that is believed to modulate $A \beta$ levels by transporting $A \beta$ from brain to the periphery [65]. Studies in patients have shown reduced levels of RBP4 in AD [66-68]. Indeed, this decrease is associated with cognitive decline, suggesting that RBP4 might be a biomarker for AD progression [66-68]. Nevertheless, it has been recently shown that RBP4 levels are not altered in preclinical AD CSF samples [63], implying that RBP4 may not be a good biomarker at preclinical stages.

The Amyloid-like protein 1 (APLP1), a member of the APP family, was found to consistently decrease in 3 independent studies. This neuron-specific protein [69] is involved in the maintenance of dendritic spines and basal synaptic transmission [70]. APLP1 is a $\gamma$-secretase substrate [71], thereby, secreted APLP1 fragments might be of especial interest to investigate $\gamma$-secretase cleavage products in $\mathrm{AD}$.

The actin-binding protein Gelsolin (GELS), which was consistently decreased in $\mathrm{AD}$ in 3 independent studies, has already been implicated in AD [72]. GELS specifically binds to $A \beta$, inhibits its aggregation and protects cells from $A \beta$-induced apoptosis [72]. Indeed, its role as a potential therapeutic strategy for $\mathrm{AD}$ treatment is currently being evaluated $[73,74]$.

The essential component of the coagulation pathway KNG1 [75], was consistently reduced in AD CSF in 3 independent proteomic studies. KNG1 is particularly attractive for further investigation since a direct relation between KNG1 and AD has not yet been reported. However, the only study which investigated KNG1 in AD (since KNG1 polymorphisms were shown to be associated with hypertension, and thereby, they hypothesized that could be cause for AD progression) showed that KNG1 polymorphisms are not correlated with the incidence of late onset $\mathrm{AD}$ in a 201 patient cohort [76].

Metallothionein-3 (MT3) was found to be consistently reduced in AD CSF (3 studies). This protein regulates $\mathrm{CNS} \mathrm{Cu}{ }^{2+}$ and $\mathrm{Zn}^{2+}$ transport and storage and inhibits the toxicity of these metals, thus representing a major component of metal homeostasis [77]; this protein thus may play an important role in $\mathrm{AD}$ progression. 
Finally, Superoxide dismutase (SODC), which neutralizes superoxide oxygen radicals to hydrogen peroxide and molecular oxygen inside the cells [78], appeared to be consistently downregulated in CSF from AD patients (3 studies). Several studies have highlighted the role of SODC deficiency in the acceleration of $\mathrm{A} \beta$ oligomerization, neuronal inflammation, and memory impairment in AD [79, 80], thus establishing SODC as an important marker in the etiopathogenesis of this disease.

Given that we only included significant data in our study, the finding that the transcription factor NFE2L2/ NRF2 was identified as the most important upstream regulator predicted to be repressed in $\mathrm{AD}$ patients is especially interesting. A reduction in this transcription factor could potentially result in several of the observed proteomics changes in $\mathrm{AD}$ [specifically underlying the reduced levels of Angiotensinogen (AGT), Complement factor D (CFAD), SCG1, Collagen alpha-1(I) chain (CO1A1), Peptidyl-prolyl cis-trans isomerase B (PPIB), SCG2, SODC and Extracellular superoxide dismutase (SODE) expression]. In this regard, it has been recently shown that NRF2 deficiency replicates the transcriptomic changes seen in Alzheimer's patients and worsens APP and tau pathology [81]. Interestingly, we also identified STK11 [also known as liver kinase B1 (LKB1)], as an upstream regulator predicted to be activated in $\mathrm{AD}$ patients. STK11 has been described as a multifunctional master kinase which is involved in a variety of functions in the nervous system such as maintaining axon integrity, neural development, neural homeostasis, neuronal survival, and control of neurotransmitter release [82]. Indeed, its deletion leads to axon degeneration [83]. Additionally, dysregulation of STK11 has been shown to contribute to $\mathrm{A} \beta$ accumulation and tauopathy AD-associated $[84,85]$.

\section{Conclusions}

Data-mining of CSF proteomic studies from individuals suffering from $A D$ retrieves and consolidates valuable information as to proteins and peptides clearly altered in $\mathrm{AD}$, information that may be useful in the constitution of a screening panel to increase the accuracy of AD diagnosis. From a methodological perspective, there are still several challenges to solve, as it is unclear which proteins or specific peptides can readily be measured in patient samples; although ELISA would work for several candidates, the low abundance of other candidates (detected exclusively by mass spectrometry) renders their quantification directly in CSF more complex. Nevertheless, the evaluation of information regarding specific peptides has not been previously performed, and the data we present herein provides direct targets towards establishing the status of a given protein in AD. These data should support the development of a peptide array with verified biomarker candidates that could move into clinical practice, even within the next few years, to fulfill the need for early detection in order to better combat this widespread neurodegenerative disease. Names of the genes and proteins cited in the text are described in Tables 3, 4 and 5.

\section{Supplementary information}

Supplementary information accompanies this paper at https://doi. org/10.1186/s12014-020-09276-9.

Additional file 1: Table S1. Information regarding all the proteins extracted from the proteomic studies. The proteins identified in each article and their abbreviations are shown. $\Delta$, proteins not recognized by DAVID bioinformatics resources, $\Pi$ qualitative but no quantitative data.

Additional file 2: Table S2. Proteins identified with significant changes between $A D$ and control samples. The number of studies that describe these changes are shown.

Additional file 3: Table S3. Proteins showing inconsistent changes in AD samples. \$ proteins which are abundant in the CSF of healthy individuals [18]. Component CO4A and CO4B are indicated as A and B respectively.

Additional file 4: Table S4. Information regarding all peptides extracted from the proteomic studies. M.W. [Da]: Molecular weight obtained from each article. Theo. M.W. [Da]: theoretical molecular weight obtained from Compute pl/Mw tool (https://web.expasy.org/compute_pi/).

Additional file 5: Table S5. Peptide sequences showing inconsistent changes in CSF studies. Peptide sequences with different pattern of expression across independent studies or inconsistent direction change to that observed by proteomics in relation to AD pathology. *Peptide sequences with changes supported by statistical analysis between $A D$ and control samples.

Additional file 6: Figure S1. Most frequently detected peptides within 13 protein sequences. Peptide sequences with the same pattern of expression in at least 2 (bold red) or 3 (bold red underlined) independent studies and maintain consistent direction change to that observed by proteomics in relation to the $A D$ pathology.

\section{Abbreviations}

AD: Alzheimer's disease; ADP: Adenosine diphosphate; AR: Age range; A 342 : Amyloid-beta 1-42; BBB: Blood-brain barrier; CDR: Clinical dementia rating scale; CE-MS: Capillary electrophoresis mass spectrometry; CERAD: Consortium to Establish a Registry for Alzheimer's Disease; CNS: Central nervous system; CSF: Cerebrospinal fluid; CT: Computed tomography; DAVID: Database for annotation, visualization and integrated discovery; DA: Daltons; DNA: Deoxyribonucleic acid; DSM: Diagnostic and statistical; ELISA: Enzyme-linked immunosorbent assay; ESI: Electrospray ionization; FAD: Familial alzheimer Disease; IAPP: Islet amyloid polypeptide; ICD-10: 10th revision of the International Statistical Classification of Diseases and Related Health Problems; ID: Identifier digital; IWG-2: International Working Group-2 criteria; IPA: Ingenuity pathway analysis; LC-MS/MS: Liquid chromatography-tandem mass spectrometry; MAP-RBM: Multi-analyte profiling technology platform- rules based medicine; MCl: Mild cognitive impairment; MCs: Mutation carriers; MEDLINE: Medical literature analysis and retrieval system online; MMSE: Mini-menta state exam; MOCA: Montreal cognitive assessment; MRI: Magnetic resonance imaging; MRM: Multiple reaction monitoring; mRNA: Messenger ribonucleic acid; MS: Mass spectrometry; NA: Not Applicable; NCs: Mutation non-carriers; NI: Not information; NIA-AA: National Institute on Aging and Alzheimer's Association; NINCDS-ADRDA: National Institute of Neurological and Communicative Disorders and Stroke and the AD and Related Disorders Association; PRM: Parallel reaction monitoring; PSEN1: Presenilin 1; p-tau: Phosphorylated tau; RNA: Ribonucleic acid; ROS: Reactive oxygen species; RP-LC MS/MS: Reversed-phase LC-MS/MS; SELDI-TOF-MS: Surface enhanced laser desorption/ionization time-of-flight mass spectrometry; SMC: Subjective memory complaints; TMT: Tandem mass tag; T-tau: Total tau; WB: Western blot. 


\section{Acknowledgements \\ Not applicable.}

\section{Authors' contributions}

All authors have made substantial contributions to the conception, drafting and editing of this work and have approved the final manuscript. All authors read and approved the final manuscript.

\section{Funding}

This study was supported by a Grant from MINECO (SAF2016-79311-R) to Mario Durán-Prado. Yoana Rabanal-Ruiz is financed by FEDER (2018/D/LD/ $\mathrm{MC} / 8)$.

\section{Availability of data and materials \\ Not applicable.}

\section{Ethics approval and consent to participate}

Not applicable.

\section{Consent for publication}

Not applicable.

\section{Competing interests}

The authors declare that they have no competing interests.

\section{Author details}

${ }^{1}$ Department of Medical Sciences, Ciudad Real Medical School, Oxidative Stress and Neurodegeneration Group, Regional Center for Biomedical Research, University of Castilla-La Mancha, Ciudad Real, Spain. ${ }^{2}$ Department of Anatomy and Neurobiology, University of Maryland School of Medicine, University of Maryland, Baltimore, MD 21201, USA

\section{Received: 22 January 2020 Accepted: 9 April 2020}

Published online: 05 June 2020

\section{References}

1. Scheltens P, Blennow K, Breteler MM, de Strooper B, Frisoni GB, Salloway S, et al. Alzheimer's disease. Lancet. 2016;388(10043):505-17.

2. Levy B, Tsoy E, Gable S. Developing cognitive markers of alzheimer's disease for primary care: implications for behavioral and global prevention. J Alzheimer's Dis. 2016;54(4):1259-72

3. Ledig C, Schuh A, Guerrero R, Heckemann RA, Rueckert D. Structural brain imaging in Alzheimer's disease and mild cognitive impairment: biomarker analysis and shared morphometry database. Sci Rep. 2018;8(1):11258

4. Anderson NL, Anderson NG. The human plasma proteome: history, character, and diagnostic prospects. Mol Cellu Proteomics. 2002:1(11):845-67.

5. Baird AL, Westwood S, Lovestone S. Blood-based proteomic biomarkers of alzheimer's disease pathology. Front Neurol. 2015;6:236.

6. Blennow K, Zetterberg H. Biomarkers for Alzheimer's disease: current status and prospects for the future. J Intern Med. 2018;284(6):643-63.

7. Blennow K. Cerebrospinal fluid protein biomarkers for Alzheimer's disease. NeuroRx J Am Soc Exp NeuroTher. 2004;1(2):213-25.

8. Rosenmann H. CSF biomarkers for amyloid and tau pathology in Alzheimer's disease. J Mol Neurosci. 2012;47(1):1-14.

9. Bjerke M, Engelborghs S. Cerebrospinal fluid biomarkers for early and differential alzheimer's disease diagnosis. J Alzheimer's Dis. 2018;62(3):1199-209.

10. Portelius E, Brinkmalm G, Pannee J, Zetterberg H, Blennow K, Dahlen R, et al. Proteomic studies of cerebrospinal fluid biomarkers of Alzheimer's disease: an update. Exp Rev Proteomics. 2017;14(11):1007-20.

11. Olsson B, Lautner R, Andreasson U, Ohrfelt A, Portelius E, Bjerke M, et al. CSF and blood biomarkers for the diagnosis of Alzheimer's disease: a systematic review and meta-analysis. Lancet Neurol. 2016;15(7):673-84.

12. Bastos P, Ferreira R, Manadas B, Moreira PI, Vitorino R. Insights into the human brain proteome: disclosing the biological meaning of protein networks in cerebrospinal fluid. Crit Rev Clin Lab Sci. 2017:54(3):185-204
13. Wesenhagen KEJ, Teunissen CE, Visser PJ, Tijms BM. Cerebrospinal fluid proteomics and biological heterogeneity in Alzheimer's disease: a literature review. Crit Rev Clin Lab Sci. 2019;57:1-13.

14. Brinkmalm G, Sjodin S, Simonsen AH, Hasselbalch SG, Zetterberg H, Brinkmalm A, et al. A parallel reaction monitoring mass spectrometric method for analysis of potential csf biomarkers for alzheimer's disease. Proteomics Clin Appl. 2018;12(1):1700131.

15. Hölttä M, Minthon L, Hansson O, Holmen-Larsson J, Pike I, Ward M, et al. An integrated workflow for multiplex CSF proteomics and peptidomicsidentification of candidate cerebrospinal fluid biomarkers of Alzheimer's disease. J Proteome Res. 2015;14(2):654-63.

16. Khoonsari PE, Haggmark A, Lonnberg M, Mikus M, Kilander L, Lannfelt $L$, et al. Analysis of the cerebrospinal fluid proteome in alzheimer's disease. PLOS ONE. 2016:11(3):e0150672.

17. Galozzi S, Marcus K, Barkovits K. Amyloid-beta as a biomarker for Alzheimer's disease: quantification methods in body fluids. Exp Rev Proteomics. 2015;12(4):343-54.

18. Schilde LM, Kosters S, Steinbach S, Schork K, Eisenacher M, Galozz $S$, et al. Protein variability in cerebrospinal fluid and its possible implications for neurological protein biomarker research. PLOS ONE. 2018;13(11):e0206478.

19. Bartolomucci A, Possenti R, Mahata SK, Fischer-Colbrie R, Loh YP, Salton SR. The extended granin family: structure, function, and biomedical implications. Endocr Rev. 2011;32(6):755-97.

20. Hendrickson RC, Lee AY, Song Q, Liaw A, Wiener M, Paweletz CP, et al. High resolution discovery proteomics reveals candidate disease progression markers of alzheimer's disease in human cerebrospinal fluid. PLOS ONE. 2015;10(8):e0135365.

21. Llano DA, Devanarayan P, Devanarayan V. VGF in cerebrospinal fluid combined with conventional biomarkers enhances prediction of conversion from MCI to AD. Alzheimer Dis Assoc Disord. 2019:33(4):307-14.

22. Eipper BA, Stoffers DA, Mains RE. The biosynthesis of neuropeptides: peptide alpha-amidation. Annu Rev Neurosci. 1992;15:57-85.

23. Bonneh-Barkay D, Wang G, Starkey A, Hamilton RL, Wiley CA. In vivo CHI3L1 (YKL-40) expression in astrocytes in acute and chronic neurological diseases. J Neuroinflamm. 2010;7:34.

24. Dhiman K, Blennow K, Zetterberg H, Martins RN, Gupta VB. Cerebrospinal fluid biomarkers for understanding multiple aspects of Alzheimer's disease pathogenesis. Cell Mol Life Sci. 2019;76(10):1833-63.

25. Rosen C, Andersson CH, Andreasson U, Molinuevo JL, Bjerke M, Rami $L$, et al. Increased levels of chitotriosidase and YKL-40 in cerebrospinal fluid from patients with alzheimer's disease. Demen Geriatr Cogn Disord Extra. 2014;4(2):297-304.

26. Baldacci F, Lista S, Palermo G, Giorgi FS, Vergallo A, Hampel H. The neuroinflammatory biomarker YKL-40 for neurodegenerative diseases: advances in development. Exp Rev Proteomics. 2019;16(7):593-600.

27. Llorens F, Thune K, Tahir W, Kanata E, Diaz-Lucena D, Xanthopoulos K, et al. YKL-40 in the brain and cerebrospinal fluid of neurodegenerative dementias. Mol Neurodegener. 2017:12(1):83.

28. Boyles JK, Pitas RE, Wilson E, Mahley RW, Taylor JM. Apolipoprotein E associated with astrocytic glia of the central nervous system and with nonmyelinating glia of the peripheral nervous system. J Clin Investig. 1985:76(4):1501-13.

29. Lloyd-Burton S, Roskams AJ. SPARC-like 1 (SC1) is a diversely expressed and developmentally regulated matricellular protein that does not compensate for the absence of SPARC in the CNS. J Comp Neurol. 2012;520(12):2575-90.

30. Lloyd-Burton SM, York EM, Anwar MA, Vincent AJ, Roskams AJ. SPARC regulates microgliosis and functional recovery following cortical ischemia. J Neurosci. 2013;33(10):4468-81.

31. Strunz M, Jarrell JT, Cohen DS, Rosin ER, Vanderburg CR, Huang X. Modulation of SPARC/Hevin proteins in alzheimer's disease brain injury. J Alzheimer's Dis. 2019;68(2):695-710.

32. Sindi IA, Tannenberg RK, Dodd PR. Role for the neurexin-neuroligin complex in Alzheimer's disease. Neurobiol Aging. 2014;35(4):746-56.

33. Lleo A, Nunez-Llaves R, Alcolea D, Chiva C, Balateu-Panos D, ColomCadena $\mathrm{M}$, et al. Changes in synaptic proteins precede neurodegeneration markers in preclinical alzheimer's disease cerebrospinal fluid. Mol Cell Proteomics. 2019;18(3):546-60.

34. Zhang Y, Marmorstein LY. Focus on molecules: fibulin-3 (EFEMP1). Exp Eye Res. 2010;90(3):374-5. 
35. Tasaki M, Ueda M, Hoshii Y, Mizukami M, Matsumoto S, Nakamura $M$, et al. A novel age-related venous amyloidosis derived from EGF-containing fibulin-like extracellular matrix protein 1. J Pathol. 2019;247(4):444-55

36. Kaufmann WA, Barnas U, Humpel C, Nowakowski K, DeCol C, Gurka P, et al. Synaptic loss reflected by secretoneurin-like immunoreactivity in the human hippocampus in Alzheimer's disease. Eur J Neurosci. 1998;10(3):1084-94

37. Lechner T, Adlassnig C, Humpel C, Kaufmann WA, Maier H, ReinstadlerKramer K, et al. Chromogranin peptides in Alzheimer's disease. Exp Gerontol. 2004;39(1):101-13.

38. Marksteiner J, Kaufmann WA, Gurka P, Humpel C. Synaptic proteins in Alzheimer's disease. J Mol Neurosci. 2002;18(1-2):53-63.

39. Willis M, Leitner I, Jellinger KA, Marksteiner J. Chromogranin peptides in brain diseases. J Neural Transm. 2011;118(5):727-35.

40. Hoshino A, Helwig M, Rezaei S, Berridge C, Eriksen JL, Lindberg I. A novel function for proSAAS as an amyloid anti-aggregant in Alzheimer's disease. J Neurochem. 2014;128(3):419-30.

41. Peinado JR, Sami F, Rajpurohit N, Lindberg I. Blockade of islet amyloid polypeptide fibrillation and cytotoxicity by the secretory chaperones 7B2 and proSAAS. FEBS Lett. 2013;587(21):3406-11.

42. Wada M, Ren CH, Koyama S, Arawaka S, Kawakatsu S, Kimura H, et al. A human granin-like neuroendocrine peptide precursor (proSAAS) immunoreactivity in tau inclusions of Alzheimer's disease and parkinsonismdementia complex on Guam. Neurosci Lett. 2004;356(1):49-52.

43. Mathys H, Davila-Velderrain J, Peng Z, Gao F, Mohammadi S, Young JZ, et al. Single-cell transcriptomic analysis of Alzheimer's disease. Nature. 2019;570(7761):332-7

44. Jahn H, Wittke S, Zurbig P, Raedler TJ, Arlt S, Kellmann M, et al. Peptide fingerprinting of Alzheimer's disease in cerebrospinal fluid: identification and prospective evaluation of new synaptic biomarkers. PLoS ONE. 2011;6(10):e26540.

45. SkillbäckT, Mattsson N, Hansson K, Mirgorodskaya E, Dahlén R, van der Flier W, et al. A novel quantification-driven proteomic strategy identifies an endogenous peptide of pleiotrophin as a new biomarker of Alzheimer's disease. Sci Rep. 2017;7(1):13333.

46. Wang J, Cunningham R, Zetterberg H, Asthana S, Carlsson C, Okonkwo $\mathrm{O}$, et al. Label-free quantitative comparison of cerebrospinal fluid glycoproteins and endogenous peptides in subjects with Alzheimer's disease, mild cognitive impairment, and healthy individuals. Proteomics Clin Appl. 2016;10(12):1225-41.

47. Swanson A, Wolf T, Sitzmann A, Willette AA. Neuroinflammation in Alzheimer's disease: pleiotropic roles for cytokines and neuronal pentraxins. Behav Brain Res. 2018;347:49-56.

48. Ma QL, Teng E, Zuo X, Jones M, Teter B, Zhao EY, et al. Neuronal pentraxin 1: a synaptic-derived plasma biomarker in Alzheimer's disease. Neurobiol Dis. 2018;114:120-8.

49. Choi YS, Hou S, Choe LH, Lee KH. Targeted human cerebrospinal fluid proteomics for the validation of multiple Alzheimer's disease biomarker candidates. J Chromatogr B Anal Technol Biomed Life Sci. 2013:930:129-35.

50. Perrin RJ, Craig-Schapiro R, Malone JP, Shah AR, Gilmore P, Davis AE, et al. Identification and validation of novel cerebrospinal fluid biomarkers for staging early Alzheimer's disease. PLoS ONE. 2011;6(1):e16032.

51. Begcevic I, Tsolaki M, Brinc D, Brown M, Martinez-Morillo E, Lazarou I, et al. Neuronal pentraxin receptor-1 is a new cerebrospinal fluid biomarker of Alzheimer's disease progression. F1000Research. 2018;7:1012

52. Abdi F, Quinn JF, Jankovic J, McIntosh M, Leverenz JB, Peskind E, et al. Detection of biomarkers with a multiplex quantitative proteomic platform in cerebrospinal fluid of patients with neurodegenerative disorders. J Alzheimer's Dis. 2006;9(3):293-348.

53. Dagur PK, Biancotto A, Stansky E, Sen HN, Nussenblatt RB, McCoy JP. Secretion of interleukin-17 by CD8 + T cells expressing CD146 (MCAM). Clin Immunol. 2014;152(1-2):36-47.

54. Dagur PK, Biancotto A, Wei L, Sen HN, Yao M, Strober W, et al. MCAMexpressing CD4(+) T cells in peripheral blood secrete IL-17A and are significantly elevated in inflammatory autoimmune diseases. J Autoimmun. 2011;37(4):319-27.

55. Larochelle C, Lecuyer MA, Alvarez Jl, Charabati M, Saint-Laurent O, Ghannam S, et al. Melanoma cell adhesion molecule-positive CD8
T lymphocytes mediate central nervous system inflammation. Ann Neurol. 2015;78(1):39-53.

56. Sommer A, Winner B, Prots I. The Trojan horse-neuroinflammatory impact of T cells in neurodegenerative diseases. Mol Neurodegener 2017;12(1):78.

57. Oberstein TJ, Taha L, Spitzer P, Hellstern J, Herrmann M, Kornhuber J, et al. Imbalance of circulating T(h)17 and regulatory $T$ cells in alzheimer's disease: a case control study. Front Immunol. 2018;9:1213.

58. Saresella M, Calabrese E, Marventano I, Piancone F, Gatti A, Alberoni M, et al. Increased activity of Th-17 and Th-9 lymphocytes and a skewing of the post-thymic differentiation pathway are seen in Alzheimer's disease. Brain Behav Immun. 2011:25(3):539-47.

59. Zhang J, Ke KF, Liu Z, Qiu YH, Peng YP. Th17 cell-mediated neuroinflammation is involved in neurodegeneration of abeta1-42-induced Alzheimer's disease model rats. PLOS ONE. 2013;8(10):e75786.

60. Dansokho C, Ait Ahmed D, Aid S, Toly-Ndour C, Chaigneau T, Calle V, et al. Regulatory T cells delay disease progression in Alzheimer-like pathology. Brain Journal Neurol. 2016;139(Pt 4):1237-51.

61. Larbi A, Pawelec G, Witkowski JM, Schipper HM, Derhovanessian E, Goldeck D, et al. Dramatic shifts in circulating CD4 but not CD8 T cell subsets in mild Alzheimer's disease. J Alzheimer's Dis. 2009;17(1):91-103.

62. Saresella M, Calabrese E, Marventano I, Piancone F, Gatti A, Calvo MG, et al. PD1 negative and PD1 positive CD4 + T regulatory cells in mild cognitive impairment and Alzheimer's disease. J Alzheimer's Dis. 2010;21(3):927-38.

63. Ishii M, ladecola C. Metabolic and non-cognitive manifestations of alzheimer's disease: the hypothalamus as both culprit and target of pathology. Cell Metab. 2015;22(5):761-76.

64. Sodhi RK, Singh N. Retinoids as potential targets for Alzheimer's disease. Pharmacol Biochem Behav. 2014;120:117-23.

65. Buxbaum JN, Reixach N. Transthyretin: the servant of many masters. Cell Mol Life Sci. 2009;66(19):3095-101.

66. Jung SM, Lee K, Lee JW, Namkoong H, Kim HK, Kim S, et al. Both plasma retinol-binding protein and haptoglobin precursor allele 1 in CSF: candidate biomarkers for the progression of normal to mild cognitive impairment to Alzheimer's disease. Neurosci Lett. 2008;436(2):153-7.

67. Maury CP, Teppo AM. Immunodetection of protein composition in cerebral amyloid extracts in Alzheimer's disease: enrichment of retinolbinding protein. J Neurol Sci. 1987;80(2-3):221-8.

68. Puchades M, Hansson SF, Nilsson CL, Andreasen N, Blennow K, Davidsson P. Proteomic studies of potential cerebrospinal fluid protein markers for Alzheimer's disease. Brain Res Mol Brain Res. 2003;118(1-2):140-6.

69. Kim TW, Wu K, Xu JL, McAuliffe G, Tanzi RE, Wasco W, et al. Selective localization of amyloid precursor-like protein 1 in the cerebral cortex postsynaptic density. Brain Res Mol Brain Res. 1995;32(1):36-44.

70. Schauenburg L, Liebsch F, Eravci M, Mayer MC, Weise C, Multhaup G. APLP1 is endoproteolytically cleaved by $\gamma$-secretase without previous ectodomain shedding. Scientific Reports. 2018;8(1):1916.

71. Sjödin S, Andersson KKA, Mercken M, Zetterberg H, Borghys H, Blennow $\mathrm{K}$, et al. APLP1 as a cerebrospinal fluid biomarker for $\mathrm{\gamma}$-secretase modulator treatment. Alzheimer's Res Ther. 2015;7(1):77.

72. Chauhan V, Ji L, Chauhan A. Anti-amyloidogenic, anti-oxidant and anti-apoptotic role of gelsolin in Alzheimer's disease. Biogerontology. 2008:9(6):381-9.

73. Carro E. Gelsolin as therapeutic target in Alzheimer's disease. Exp Opinion Ther Targets. 2010;14(6):585-92.

74. Ji L, Zhao X, Hua Z. Potential therapeutic implications of gelsolin in Alzheimer's disease. J Alzheimer's Dis. 2015:44(1):13-25.

75. Brunel H, Massanet R, Martinez-Perez A, Ziyatdinov A, Martin-Fernandez $\mathrm{L}$, Souto JC, et al. The central role of KNG1 gene as a genetic determinant of coagulation pathway-related traits: exploring metaphenotypes. PLOS ONE. 2016;11(12):e0167187.

76. Deng Y, Hou D, Tian M, Li W, Feng X, Yu Z. Relationship between the gene polymorphisms of kallikrein-kinin system and Alzheimer's disease in a Hunan Han Chinese population. Int J Clin Exp Pathol. 2015;8(12):15550-62

77. Vašák M, Meloni G. Mammalian metallothionein-3: new functional and structural insights. Int J Mol Sci. 2017;18(6):1117.

78. Estacio SG, Leal SS, Cristovao JS, Faisca PF, Gomes CM. Calcium binding to gatekeeper residues flanking aggregation-prone segments underlies 
non-fibrillar amyloid traits in superoxide dismutase 1 (SOD1). Biochem Biophys Acta. 2015;1854(2):118-26.

79. McLimans KE, Clark BE, Plagman A, Pappas C, Klinedinst B, Anatharam V et al. Is cerebrospinal fluid superoxide dismutase 1 a biomarker of Tau but not amyloid-induced neurodegeneration in alzheimer's disease? Antioxid Redox Signal. 2019;31(8):572-8.

80. Murakami K, Murata N, Noda Y, Tahara S, Kaneko T, Kinoshita N, et al. SOD1 (copper/zinc superoxide dismutase) deficiency drives amyloid beta protein oligomerization and memory loss in mouse model of Alzheimer disease. J Biol Chem. 2011;286(52):44557-68.

81. Rojo Al, Pajares M, Rada P, Nunez A, Nevado-Holgado AJ, Killik R, et al. NRF2 deficiency replicates transcriptomic changes in Alzheimer's patients and worsens APP and TAU pathology. Redox Biol. 2017;13:444-51.

82. Kuwako $\mathrm{Kl}, \mathrm{Okano} \mathrm{H}$. Versatile roles of LKB1 kinase signaling in neural development and homeostasis. Front Mol Neurosci. 2018;1 1:354.

83. Sun G, Reynolds R, Leclerc I, Rutter GA. RIP2-mediated LKB1 deletion causes axon degeneration in the spinal cordand hind-limb paralysis. Dis Model Mech. 2011;4(2):193-202.

84. Kodamullil AT, Younesi E, Naz M, Bagewadi S, Hofmann-Apitius M. Computable cause-and-effect models of healthy and Alzheimer's disease states and their mechanistic differential analysis. Alzheimer's Demen. 2015;11(11):1329-39.

85. Wang JW, Imai Y, Lu B. Activation of PAR-1 kinase and stimulation of tau phosphorylation by diverse signals require the tumor suppressor protein LKB1. J Neurosci. 2007;27(3):574-81.

86. Whelan CD, Mattsson N, Nagle MW, Vijayaraghavan S, Hyde C, Janelidze S, et al. Multiplex proteomics identifies novel CSF and plasma biomarkers of early Alzheimer's disease. Acta Neuropathol Commun. 2019;7(1):169.

87. Khoonsari PE, Shevchenko G, Herman S, Remnestal J, Giedraitis V Brundin R, et al. Improved Differential Diagnosis of Alzheimer's Disease by Integrating ELISA and Mass Spectrometry-Based Cerebrospinal Fluid Biomarkers. J Alzheimers Dis. 2019;67(2):639-51.

88. Sathe $\mathrm{G}, \mathrm{Na} \mathrm{CH}$, Renuse $\mathrm{S}$, Madugundu AK, Albert M, Moghekar A, et al. Quantitative Proteomic Profiling of Cerebrospinal Fluid to Identify Candidate Biomarkers for Alzheimer's Disease. Proteomics Clin Appl. 2019;13(4):e1800105

89. Duits FH, Brinkmalm G, Teunissen CE, Brinkmalm A, Scheltens P, Van der Flier WM, et al. Synaptic proteins in CSF as potential novel biomarkers for prognosis in prodromal Alzheimer's disease. Alzheimers Res Ther. 2018;10(1):5.

90. Dayon L, Nunez Galindo A, Wojcik J, Cominetti O, Corthesy J, Oikonomidi $A$, et al. Alzheimer disease pathology and the cerebrospinal fluid proteome. Alzheimers Res Ther. 2018;10(1):66.

91. Paterson RW, Heywood WE, Heslegrave AJ, Magdalinou NK, Andreasson $\mathrm{U}$, Sirka E, et al. A targeted proteomic multiplex CSF assay identifies increased malate dehydrogenase and other neurodegenerative biomarkers in individuals with Alzheimer's disease pathology. Transl Psychiatry. 2016;6(11):e952.

92. Remnestal J, Just D, Mitsios N, Fredolini C, Mulder J, Schwenk JM, et al. CSF profiling of the human brain enriched proteome reveals associations of neuromodulin and neurogranin to Alzheimer's disease. Proteomics Clin Appl. 2016;10(12):1242-53.

93. Di Domenico F, Pupo G, Giraldo E, Badia MC, Monllor P, Lloret A, et al. Oxidative signature of cerebrospinal fluid from mild cognitive impairment and Alzheimer disease patients. Free Radic Biol Med. 2016;91:1-9.

94. Heywood WE, Galimberti D, Bliss E, Sirka E, Paterson RW, Magdalinou NK, et al. Identification of novel CSF biomarkers for neurodegeneration and their validation by a high-throughput multiplexed targeted proteomic assay. Mol Neurodegener. 2015;10:64.

95. Spellman DS, Wildsmith KR, Honigberg LA, Tuefferd M, Baker D, Raghavan N, et al. Development and evaluation of a multiplexed mass spectrometry based assay for measuring candidate peptide biomarkers in Alzheimer's Disease Neuroimaging Initiative (ADNI) CSF. Proteomics Clin Appl. 2015;9(7-8):715-31.

96. Leung YY, Toledo JB, Nefedov A, Polikar R, Raghavan N, Xie SX, et al. Identifying amyloid pathology-related cerebrospinal fluid biomarkers for Alzheimer's disease in a multicohort study. Alzheimers Dement (Amst). 2015;1(3):339-48.
97. Khan W, Aguilar C, Kiddle SJ, Doyle O, Thambisetty M, Muehlboeck S, et al. A subset of cerebrospinal fluid proteins from a multi-analyte panel associated with brain atrophy, disease classification and prediction in Alzheimer's disease. PloS one. 2015;10(8):e0134368.

98. Oláh Z, Kalman J, Toth ME, Zvara A, Santha M, Ivitz E, et al. Proteomic analysis of cerebrospinal fluid in Alzheimer's disease: wanted dead or alive. Journal of Alzheimer's disease : JAD. 2015;44(4):1303-12.

99. Alzate O, Osorio C, DeKroon RM, Corcimaru A, Gunawardena HP. Differentially charged isoforms of apolipoprotein $\mathrm{E}$ from human blood are potential biomarkers of Alzheimer's disease. Alzheimers Res Ther. 2014;6(4):43.

100. Wildsmith KR, Schauer SP, Smith AM, Arnott D, Zhu Y, Haznedar J, et al. Identification of longitudinally dynamic biomarkers in Alzheimer's disease cerebrospinal fluid by targeted proteomics. Mol Neurodegener. 2014;9:22.

101. Chakrabarti A, Chatterjee A, Sengupta MB, Chattopadhyay P, Mukhopadhyay D. Altered levels of amyloid precursor protein intracellular domain-interacting proteins in Alzheimer disease. Alzheimer Dis Assoc Disord. 2014;28(3):283-90.

102. Wijte D, McDonnell LA, Balog Cl, Bossers K, Deelder AM, Swaab DF, et al. A novel peptidomics approach to detect markers of Alzheimer's disease in cerebrospinal fluid. Methods. 2012;56(4):500-7.

103. Ringman JM, Schulman H, Becker C, Jones T, Bai Y, Immermann F, et al. Proteomic changes in cerebrospinal fluid of presymptomatic and affected persons carrying familial Alzheimer disease mutations. Arch Neurol. 2012;69(1):96-104.

104. Manral P, Sharma P, Hariprasad G, Chandralekha, Tripathi M, Srinivasan A. Can apolipoproteins and complement factors be biomarkers of Alzheimer's disease? Curr Alzheimer Res. 2012;9(8):935-43.

105. Vafadar-Isfahani B, Ball G, Coveney C, Lemetre C, Boocock D, Minthon $\mathrm{L}$, et al. Identification of SPARC-like 1 protein as part of a biomarker panel for Alzheimer's disease in cerebrospinal fluid. J Alzheimers Dis. 2012;28(3):625-36.

106. Craig-Schapiro R, Kuhn M, Xiong C, Pickering EH, Liu J, Misko TP, et al. Multiplexed immunoassay panel identifies novel CSF biomarkers for Alzheimer's disease diagnosis and prognosis. PloS one. 2011;6(4):e18850

107. Hu WT, Chen-Plotkin A, Arnold SE, Grossman M, Clark CM, Shaw LM et al. Novel CSF biomarkers for Alzheimer's disease and mild cognitive impairment. Acta neuropathologica. 2010;119(6):669-78.

108. Maarouf CL, Andacht TM, Kokjohn TA, Castano EM, Sue LI, Beach TG, et al. Proteomic analysis of Alzheimer's disease cerebrospinal fluid from neuropathologically diagnosed subjects. Curr Alzheimer Res. 2009;6(4):399-406.

109. Yin GN, Lee HW, Cho J-Y, Suk K. Neuronal pentraxin receptor in cerebrospinal fluid as a potential biomarker for neurodegenerative diseases. Brain Res. 2009:1265:158-70.

110. Zhang J, Sokal I, Peskind ER, Quinn JF, Jankovic J, Kenney C, et al. CSF multianalyte profile distinguishes Alzheimer and Parkinson diseases. Am J Clin Pathol. 2008;129(4):526-9.

111. Simonsen AH, McGuire J, Hansson O, Zetterberg H, Podust VN, Davies $H A$, et al. Novel panel of cerebrospinal fluid biomarkers for the prediction of progression to Alzheimer dementia in patients with mild cognitive impairment. Arch Neurol. 2007;64(3):366-70.

112. Hu Y, Hosseini A, Kauwe JS, Gross J, Cairns NJ, Goate AM, et al. Identification and validation of novel CSF biomarkers for early stages of Alzheimer's disease. Proteomics Clin Appl. 2007;1(11):1373-84.

113. Korolainen MA, Nyman TA, Nyyssonen P, Hartikainen ES, Pirttila T. Multiplexed proteomic analysis of oxidation and concentrations of cerebrospinal fluid proteins in Alzheimer disease. Clin Chem. 2007;53(4):657-65.

114. Finehout EJ, Franck Z, Choe LH, Relkin N, Lee KH. Cerebrospinal fluid proteomic biomarkers for Alzheimer's disease. Ann Neurol. 2007:61(2):120-9.

115. Simonsen AH, McGuire J, Podust VN, Davies H, Minthon L, Skoog I, et al. Identification of a novel panel of cerebrospinal fluid biomarkers for Alzheimer's disease. Neurobiol Aging. 2008;29(7):961-8.

116. Castaño EM, Roher AE, Esh CL, Kokjohn TA, Beach T. Comparative proteomics of cerebrospinal fluid in neuropathologically-confirmed Alzheimer's disease and non-demented elderly subjects. Neurol Res. 2006:28(2):155-63. 
117. Selle H, Lamerz J, Buerger K, Dessauer A, Hager K, Hampel H, et al. Identification of novel biomarker candidates by differential peptidomics analysis of cerebrospinal fluid in Alzheimer's disease. Comb Chem High Throughput Screen. 2005;8(8):801-6.

118. Zhang J, Goodlett DR, Quinn JF, Peskind E, Kaye JA, Zhou Y, et al. Quantitative proteomics of cerebrospinal fluid from patients with Alzheimer disease. J Alzheimers Dis. 2005;7(2):125-33 (discussion 73-80).

119. Carrette O, Demalte I, Scherl A, Yalkinoglu O, Corthals G, Burkhard P, et al. A panel of cerebrospinal fluid potential biomarkers for the diagnosis of Alzheimer's disease. Proteomics. 2003;3(8):1486-94.
120. Davidsson P, Westman-Brinkmalm A, Nilsson CL, Lindbjer M, Paulson L, Andreasen $\mathrm{N}$, et al. Proteome analysis of cerebrospinal fluid proteins in Alzheimer patients. Neuroreport. 2002;13(5):611-5.

\section{Publisher's Note}

Springer Nature remains neutral with regard to jurisdictional claims in published maps and institutional affiliations.
Ready to submit your research? Choose BMC and benefit from:

- fast, convenient online submission

- thorough peer review by experienced researchers in your field

- rapid publication on acceptance

- support for research data, including large and complex data types

- gold Open Access which fosters wider collaboration and increased citations

- maximum visibility for your research: over 100M website views per year

At BMC, research is always in progress.

Learn more biomedcentral.com/submissions 